\title{
Play in the smart city context: exploring interactional, bodily, social and spatial aspects of situated media interfaces
}

\author{
Andre G. Afonso \\ andre.afonso.13@ucl.ac.uk \\ The Bartlett School of Architecture \\ University College London, UK
}

\author{
Ava Fatah gen. Schieck \\ ava.fatah@ucl.ac.uk \\ The Bartlett School of Architecture \\ University College London, UK
}

Corresponding author: Andre G. Afonso

Keywords: urban media installations, social encounters, playful interface, fountain.

\begin{abstract}
Urban media interfaces can assume many forms, offering rich possibilities for interactions and social encounters. We focus on a particular type of urban interfaces, namely urban media installations, which are situated, fixed (i.e. non-mobile) and outdoor interactive interfaces enhanced by digital technologies. Drawing on research on play in the context of the smart city, we aim to clarify how the digital and the physical worlds of urban media installations can coalesce into enjoyable and socially thriving playscapes. Two case studies of urban media installations featuring high levels of interactivity and playfulness are presented: the Appearing Rooms, a seasonal art installation in London, and the Mirror Pool, a permanent, large-scale urban installation in Bradford, UK. Each of these interfaces incorporates a design paradigm that differs from the other in terms of context, duration of implementation, and scale. Following a longitudinal approach based on non-participant observations and timelapse photography, we analyse emergent interactions and focus in particular on playful encounters at different levels and scales: from the micro scale of the bodily engagement to the macro scale of the spatial and social configurations. Our case studies highlight that the urban spatial layout is a key element in defining the emerging interactions and encounters around the urban situated interfaces. We suggest, within the premise of the "smart city", that digital technologies can have an active role, with a great potential to encourage playful experiences and shared encounters in urban spaces; yet the digital should be coupled with a careful consideration of the spatial, physical, material and bodily aspects of interactions, that are fundamental to our lived experience of the city.
\end{abstract}

\section{Introduction}

One important function of public space is providing citizens with a setting where they can encounter each other, interact with the environment and engage in playful activities. Yet, play as a mode for creative experimentation, can help us make meaning and understand how we can impact the world around us and affect change (Kress and Cowan, 2017). As such the concept of "urban play" emphasises a unique character of the urban experience: it is related to the ways people sense urban settings, move through them and act within them. Urban play embraces a wide variety of activities, which are spontaneous, irrational or risky, and often unanticipated by designers, managers and other users (Stevens, 2007).

The growing use and implementation of digital technologies is redefining how people engage in urban spaces, with the environment itself and with other people (Katharine et al, 2008, Fatah gen Schieck et al, 2008, de Waal, 2014, de Lange and de Wall, 2019). The rise of urban media interfaces seems to stimulate a spatial shift: by coupling the digital with the physical, urban media can enable spaces for playful and social interactions that are more flexible and less dependent on the rigid structures of the built environment (Pop et al, 2016). At the same time, playful experiences become available to a new public: children are no longer the sole players, as new agents and communities arise from playscapes enhanced by emergent technologies. Within this trend, and since technologies make it possible in some situations to re-configure new conditions for playful activities that can potentially transform the experience of any urban environment, conventional facilities such as dedicated playgrounds cease to be the only site for play.

New types of playful interfaces, whether mobile or fixed, have emerged over the years. In the context of mobile interfaces, Luke (2006) talks about the role of mobile phones in having a playful orientation to city spaces, while Saker and Evans (2016) point to the concept of the "playeur" as an individual who reads city spaces as a site of 
play and who makes connections within the city contingent on mood or orientation. From a design standpoint, Verhoeff argues that media architecture technologies are inherently mobile and temporal, which makes the very process of designing them a performative process: the design does not merely precede the interface, but is rather performed in it; there is no rigorous distinction between "process" and "product" (Verhoeff, 2015). However, playful interactions can also rely on other types of interfaces, such as the ones that remain fixed in their settings either temporarily or permanently. These fixed, and situated interfaces may carry a great potential to encourage not only playful behaviours, but also social encounters, bodily interactions and social learning and even act as platforms of socio- political critique. An interesting example of the latter case is the series of seesaws designed by Ronald Rael and Virginia San Fratello, which were installed at the steel border fence that separates the United States from Mexico. Once installed, the pink seesaws were promptly appropriated by children and adults located at either sides of the border. Their playful interactions, locally and bodily performed, rapidly assumed a global meaning through the intangible interfaces of social media and communication networks. Among other aspects, this initiative is noteworthy because it responds to a serious political, social and spatial crisis in a playful, evocative and light-hearted fashion. According to Rael, besides bringing a sense of togetherness at the border fence, the project is about recognizing that the actions that take place on one side have a direct consequence on the other side (The Guardian, 2019).

One prominent example of the interactive interface is the urban media installation: a fixed interface that creates an interaction space on a public open area, allowing several people to physically explore and share the interface at once. Urban media installations may be employed on a temporary or permanent basis. Those installed on a permanent basis tend to become embedded elements in the urban settings, just like a piece of architecture or landscaping feature. A central feature of urban media installations (and what distinguishes them from mere sculptures or conventional art installations) is the use of digital technologies - encapsulated in the term media, which ultimately mediate how people experience and share the interface and its surrounding space (Pop et al, 2016).

The types of urban media that are installed on a permanent, long-term or seasonal basis are becoming more common in recent years, due to recent technological innovations, coupled with a heightened awareness of the social, spatial and economic benefits brought about by these installations. From a socio-spatial perspective, these situated and fixed interfaces have given rise to new forms of bodily and playful interactions that, unlike those mediated through mobile media, present a highly situated character insofar as they are fixed interfaces, embedded in their places of interaction (Afonso et al, 2019). Being fixed and embedded interfaces means that players are often encouraged to interact with urban media installations not through a portable personal screen - as typified by mobile interfaces - but rather by using their whole bodies and sensory apparatuses to explore the space, the materiality and the three-dimensionality of the installation. While engaging with urban media installations, people become aware not only of their own interactions, but also of other people's actions and behaviours; eventually, the entire socio-spatial environment becomes part of the playscape, with players' bodily positions and movements constantly negotiated, both in relation to other players, and in relation to the spatial arrangement of the installation, which define different interaction spaces (Fischer and Hornecker 2012).

Urban media installations, as embodied and, to some extent, tangible structures situated in public settings, affect not only the behaviour of individual passers-by, but also change the spatial and social dynamics around them (Behrens et al, 2015, Fatah gen Schieck et al, 2008). At the same time, the existing physical space is not a passive "platform" for the installation (Behrens et al, 2013): the spatial layout plays a vital role in defining how the interface will be approached, used and shared. Media architecture and urban digital interaction scholars have discussed the social and spatial aspects of introducing media installations in outdoor public settings, and key concepts have been proposed, such as "Urban HCI" and "social affordances" (Afonso et al, 2019). On the one hand, most of these concepts emerge from studies of media interfaces that were only temporarily implemented, hence with little consideration of two fundamental aspects concerning urban spaces and the city context. Firstly, studies addressing temporary interfaces typically lack a more profound discussion regarding the wider urban context, with its various nuances, levels and scales of analysis. In terms of scale, for example, interactions with urban media range from the micro scale of the bodily engagement to the macro scale of the spatial and social configurations around the installation. Secondly, little attention is paid to the role of the physical space as enabler and generator of individual and shared encounters, in particular those that take place around urban interfaces installed on a permanent or long-term basis. On the other hand, research on interaction with permanent digital interfaces as part of architectural space (mostly in the form of vertical surfaces), addresses a situation that requires people to use another tangible device - a "mediator" (Behrens et al 2013) - to interact with the interface, which remains detached from a direct bodily connection and sensation.

We address the gaps in literature outlined above by exploring in depth two urban media installations in which water is an important feature, and whose permanent (or semi-permanent) character makes them embedded elements within their urban surroundings. In this case, a range of factors concerning, for example, spatial layout, locational attributes, urban structure and pedestrian flows inform the design of the installations, which should fit the socio-spatial environment in which they are situated. Taking inspiration from the phenomenological 
assumption that our experiences in the world are inherently rooted in our perceiving, sensing and acting bodies ${ }^{1}$, coupled with ideas from architectural research that draws on space (in terms of spatial configurations) as an enabler for shared encounters (in terms of spatial configurations) ${ }^{2}$, we focus the discussion on urban interfaces supported by digital technologies and designed to encourage playful experiences and shared encounters through whole-body interactions.

Two case studies of existing urban media installations are presented: the Appearing Rooms, a seasonal interactive art installation in London, and the Mirror Pool, a permanent installation of a massive fountain which is the centrepiece of a project of urban regeneration in Bradford, UK. Each system incorporates a design paradigm which is markedly different from the other, both in terms of context (one as a self-contained artwork, the other embedded in a project of urban design), time (one as a seasonal installation, the other as a permanent addition to the city), and scale (one measuring approx. 50 sq. m, the other approx. 3,600 sq. m). As situated and fixed media, the case studies also differ in the way they employ digital technologies: in the Appearing Rooms, players engage with the water, not with the computing device that controls the water behaviour (back-end model of interaction), ${ }^{3}$ whereas in the Mirror Pool players can have a more direct experience of the digital technologies that mediate their interactions (back-end and front-end models) ${ }^{4}$, particularly when the motion sensor-controlled laser lights of the installation are activated every night. We analyse how these playful interfaces help shape lived experiences at different levels and scales: from the micro scale of the bodily engagement to the macro scale of the spatial and social configurations unfolding on each urban context.

These case studies allow for a rich and nuanced discussion on playful interactions in urban spaces, particularly in the context of smart cities. We interpret "smart" spaces as those enabling meaningful urban experiences, considered both from the perspective of the body (i.e. the physical, material, sensory qualities that render a space enticing for the lived body) and also from a socio-spatial perspective (the diverse community of players and other people who share and give life to these spaces, either temporarily - the case of Appearing Rooms - or through long-term relationships - the Mirror Pool).

Addressing the lived, bodily and playful experience of the city calls for an approach that foregrounds the material, tangible qualities of human interactions with situated technologies. In this regard, the two interfaces discussed in this paper share a significant feature: they exploit water as the basic material for interaction, following a long tradition in urban design (which has valued the water for its ecological, economic, topological and scenic qualities), yet reinterpreting the bodily experience of water in light of emergent digital interactive technologies. By analysing and comparing the bodily, social and spatial aspects that shape how people experience these two urban interfaces, we aim to clarify how the digital and the physical worlds can coalesce into enjoyable and socially thriving playscapes.

\section{Background}

We begin this section addressing urban design and providing a brief historical account of how the fields of architecture and urban design have discussed the concept of play, considered as the "non-functional uses of public spaces". This is followed by an outline of the effect of new technologies - specifically digital technologies - on urban design and their wide, potentially disruptive implications on all levels for the future of cities (Kitchin, 2014; 2015). We sketch out the main trends in the literature of the so-called "smart cities" initiatives; however, instead of focusing on data and information-heavy urban environments, we will re-think "smart cities" as playable cities (Ackermann et al 2016; Sicart 2016). This approach will be illustrated with examples of projects exploring playful interactions mediated by digital technologies that extend the conventional notion of "play" into new dimensions, in which the sensory-kinaesthetic experience of the player assumes a central role. The section ends with a transition towards the use of water in urban design and how it supports playful forms of encounters and its manifestation through new digital forms, the typology of interface that will be later the focus of our discussions through our case studies.

\section{Play and urban design}

Dutch cultural historian Johan Huizinga, who coined the concept of Homo Ludens, stated that play is older than culture (Huizinga 1955). Yet, as far as urban design history is concerned, proper spaces for play were rare in the West, with the exception of classical Greek and Roman arenas. Until the late nineteenth century, play unfolded mostly in shared grounds, thus leaving no significant traces. Le Corbusier's 1933 Radiant City marked the turning point where play, and especially sport, became a core concern for urban design (Pérez de Arce 2018).

\footnotetext{
' Merleau-Ponty 2012; Ihde 1990; Dourish 2001; Seamon 2007; Winograd \& Flores 1986; Ciolfi 2004.

Hillier 1996a.

Back-end refers to the use of digital technologies only to control the installation's behaviour.

* Back-end and front-end refer to the use of digital technologies on both ends of the installation; 1) to control the installation's behaviour (behind the scene) and 2) as a mediator for interactions among people (as part of the main interaction scence).
} 
Among the core characteristics of play, scholars have identified its non-functional and non-utilitarian character. Stevens (2007), for example, links play to non-instrumental behaviour; for van Vleet and Feeney (2015), play involves a focus on the process of the activity and implicit learning, rather than end-goals, whereas for Kwastek (2013, p. 72), the common feature to all forms of play is the "foundation of an experience on an activity that is not primarily purposeful." However, in the context of urban settings, Stevens (2007) argues that, until not long ago, few relevant empirical studies had addressed the non-functional uses of public spaces - despite the importance of this subject to better understanding and developing the very concept of play.

An early study that acknowledged playful behaviour as a key element to create lively places is Suzanne and Henry Lennard's book Public life in urban places, in which the authors observe that "providing an opportunity to relate in a playful and joyous mode is a contribution made by good public spaces towards the well being of their users" (Lennard and Lennard 1984, p. 9). Sicart, on the other hand, calls for scholars as well as designers to think about playful interactions as a valuable interface and design practice, and reminds us in his article Play and the City (2016), that playful engagement with urban environments has offered a mode of resistance and appropriation of cities for their citizens.

More recently, architectural research has paid more attention to the various forms of play in urban spaces, with important contributions arising from different perspectives, such as Iain Borden's work on skateboarding. ${ }^{5}$ Although Borden's main interest does not lie in play itself, the notion of play is often revealed as the author discusses the history and practice of skateboarding, an activity that entails a playful approach to the city. Borden's research is particularly relevant to our discussion because the practice of skateboarding, as explored by the author, generates a domain of outdoor interactions that is deeply rooted in the idea of bodily engagement, which Borden uses to underpin a "performative critique" of architectural and urban design: "above all, it is in the continual performance of skateboarding - which, rather than reading or writing the city, speaks the city through utterance as bodily engagement - that its meaning and actions are manifested" (Borden 2001, p. 195, emphasis on original).

\section{Play in the context of the smart city}

As far as debates on digital cities are concerned, the turn of the millennium marked a shift in focus from 'cyber space' to 'ubiquitous computing'. Urban spaces have acquired a digital layer, which involves the design of organisations, services and communications. Digital technology is built into our environments and embedded in our devices, pervading our everyday lives. Increasingly, these technologies are networked and potentially disruptive, as exemplified by the notion of smart city, a highly debated model of urban development led by industrial and governmental initiatives.

Overall, literature on 'smart cities' seems to follow one of two trends: the first tends to promote a positive and rather simplistic view of smart urbanism with the focus on management and organisations; whereas the second trend represents a more critical view, focusing mainly on 'place' as location for political and socio-economic agency. Within the second trend, some authors have characterized the smart city model as a high-profile financial and political drive to smarten the built environment following a logic of technocracy (Carvalho, 2015) and appraisals for progress (Catapult Future Cities, 2017). A community-oriented alternative to such corporationoriented notion of "smart city" has informed the Playable City initiative. Spanning various cities across five continents, the Playable City aims to generate a worldview of "smarter city" development by fostering creative technology-driven projects, which are sensitive to site-specific issues and opportunities (Playable City, 2019). Such site-specific, place-based approach to the concept of "smart city" allows each community to tackle its own urban problems creatively.

Urban initiatives like the Playable City draw our attention to the importance of interactivity beyond the scale of the object and the task at hand. Key to this development is the notion of space, which calls for a coupling of urban design and interaction design. Such coupling may pave the way for novel approaches concerning how our cities are shaped, and how to deal with a variety of urban problems in light of emerging interactive technologies. From that viewpoint, it is important to explore other approaches to the implementation of digital technologies, and their impact on the practice of urban design.

Troy Innocent $(2016,2020)$, for instance, reframes the relationship of citizens to the city as 'players' and introduces three concepts that connect play and placemaking in cities: the "urban art environment", a constructed playground in urban space; "mixed realities and urban art", or the framing of the city as a playground; and the "playful citizen", which reframes the relationship of the player to the city. Sicart (2016) reminds us that data created by smart cities can provide access to information-heavy urban environments on the level of human-scaled experiences, not

\footnotetext{
"See, for example: Borden 1996. Strangely familiar: narratives of architecture in the city; Borden 2001. Another pavement, another beach: skateboarding and the performative critique of architecture. In I. Borden et al (Eds.), The unknown city: contesting architecture and social space: a Strangely Familiar project; Borden 2014. The role of risk in urban design. In Carmona, M. (Ed.). Explorations in Urban Design: An Urban Design Research Primer.
} 
necessarily presented as a service for citizens but rather as a support for play. According to him, data-rich cities can become playable cities, and, as such, more human and more inclusive spaces. Nijholt $(2017,2020)$ outlines the need to address other aspects of smart cities that relate to our daily life activities, activities that are undertaken without having any type of efficiency in mind and interactions in which we want to engage just for social, entertainment, and fun reasons, where residents have the possibility to hack the city and use the smart city's data and digital technology for their own purposes and applications. According to him, the infrastructure of a smart city can be adapted to playful applications that residents have in mind, or smart city residents can hack the environment and embed their own technology in an existing global network.

With regard to the practice of urban design, as projects increasingly embrace the idea of playfulness mediated though digital technologies, it becomes clear that playful spaces and interfaces do offer a great potential for creating activating urban spaces. However, as far as play is concerned, some recent projects have shown that the mere intention or indeed the presence of a playful infrastructure is far from assuring playful behaviours, let alone empirically observed benefits in terms of social encounters or urban livelihood. A good example of this is the Granary Square fountains ${ }^{6}$, part of an ongoing major project of urban redevelopment in central London (Argent St. George 2001; Zielinska-Dabkowska et al. 2019). The Granary Square fountains incorporate a cutting-edge technology that enables members of the public to control the behaviour of their 1,080 water jets through a dedicated mobile app.
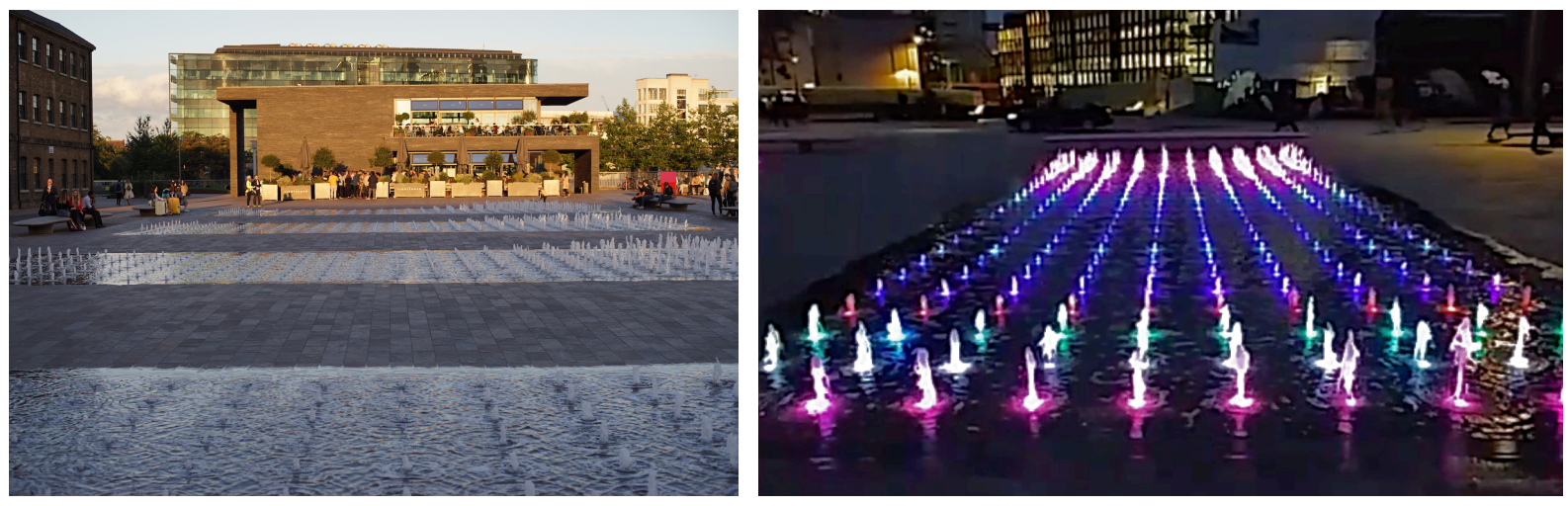

Figure 1. Views of the Granary Square fountains during the day (left) and at night, with the illuminated jets (right). After downloading the mobile app Granary Squirt, and accessing the local Wi-Fi network, people can use their mobile phones to play an urban-scale, water-based version of the game Snake - in which players control, in real time, a line of jets - or a "water snake" - as it makes its way across the four fountain bays shown above'.

Since this ingenious and playful feature was launched, a few years ago, we have been systematically visiting the site and, surprisingly, virtually no player was found engaging with the game. In the summer, plenty of social encounters and playful behaviours do take place within and around the fountains of Granary Square; yet none of these social activities were sparked by the site-specific game, no matter the season or weather conditions.

This gap between a designed experience (the urban game itself) and the ways people actually experience their everyday urban settings illustrates a relatively common situation in the fields of architectural and urban design. As philosopher Henri Lefebvre (1991) explains through his concepts of "conceived space" and "lived space", when urban strategies, designs and mechanisms (the conceived space) do not meet basic requirements for the (playful) experience of local conditions (the lived space), the ideas or plans at stake - no matter how innovative they are remain detached from the reality of embodied, situated urban experiences.

\section{Spatial and social approaches to interactions with situated urban media}

Within the context of smart cities, as we witness a new wave of implementations of situated urban media that run on a permanent or long-term basis, it seems necessary to engage in a much deeper and broader debate of the spatial and social implications of the urban media than those found in literature to date. In particular, it is fundamental to address the mechanisms whereby situated installations mediate an entire domain of urban experiences, with due attention to the role of the physical space as enabler and generator of individual and shared experiences and encounters. Previous research on urban media installations has already developed interaction frameworks that help to shed light on various aspects regarding the use and sharing of playful outdoor installations activated by digital technologies, and how this affects the surrounding physical space (Afonso et al, 2019). A similar spatial concern

- Developed by The Fountain Workshop (the same team responsible for the Mirror Pool, one of our case studies).

Up to eight people can play the game simultaneously. The game is activated in Granary Square daily, normally during a one-hour time slot, which varies according to the season. Further details on: https://www.kingscross.co.uk/granary-squirt 
informed the development of the "media architectural interface" framework (Behrens et al, 2015), which provides a synthesis of situated and shared interfaces.

Research has also looked into interactions mediated through tangible interfaces (Müller et al. 2010), exploring the connections between various situated digital surfaces installed vertically and horizontally. They found that changing the properties of one component directly affects the other elements. These elements, in turn, set the level of participation (Fritsch and Brynskov, 2011; Caldwell and Foth 2014) and, in some urban situations, may amplify participants' interactions, depending on the properties of the interface and its socio-spatial setting (for example, a busy high street or a transport hub). Other authors have focused on the social aspects of interactions with urban media interfaces, and how these interfaces support shared encounters in public spaces by bringing people together and by creating a setting for unplanned situations, conversations and site-specific experiences (Fatah gen Schieck et al, 2008).

Altogether, the body of research outlined above reinforces our argument that situated urban media installations represent a multi-layered phenomenon and, as such, have the capacity to mediate new experiences and stimulate new forms of engagements, both individually and collectively. At the individual level, urban installations lend themselves to numerous forms of bodily engagement: they encourage people to move, to feel and to interact with the interface itself, with the spatial setting and with other people - as they wish, often triggering playful behaviours (Fatah gen Schieck, 2008; Urbanowicz and Lucyna 2012). At the collective level, urban installations are public and situated structures and, as such, they often function as a playful arena, able to spark many types of social encounters; these may take place via "triangulation" (prompting strangers to talk to each other), or via "shared encounters" (in which a sense of performative co-presence is experienced) (Reeves, 2011; Benford and Giannachi, 2011).

\section{Water in urban design: from contemplation to play}

Urban design has a very long tradition in exploiting water features for manifold reasons. The very history of civilizations and urban societies is closely tied to the element of water; suffice it to say that the first known human settlements were established and developed alongside water streams: "all civilization originally was a river civilization" (Niederland, 1989, p. 43). Since those early settlements, water has been harnessed in cities for an ever-increasing variety of uses that exploit, for example, its utilitarian, economic, ecological, symbolic and scenic qualities. Especially relevant to this research, though, are the interactional and playful characteristics of water in public outdoor spaces, and how this notion has developed over time in light of new technologies.

A pedestrian crossing the lower level of the Trafalgar Square, in Central London, may feel enticed to approach one of the monumental fountains and, possibly, also spare some time lingering and resting on the fountain's borders, as shown in Figure 2. Trafalgar Square's aquatic facilities illustrate one of the most ubiquitous design typologies of fountains, which are essentially conceived as urban amenities that encourage passive, contemplative behaviours, and, to different degrees, also informal social encounters.

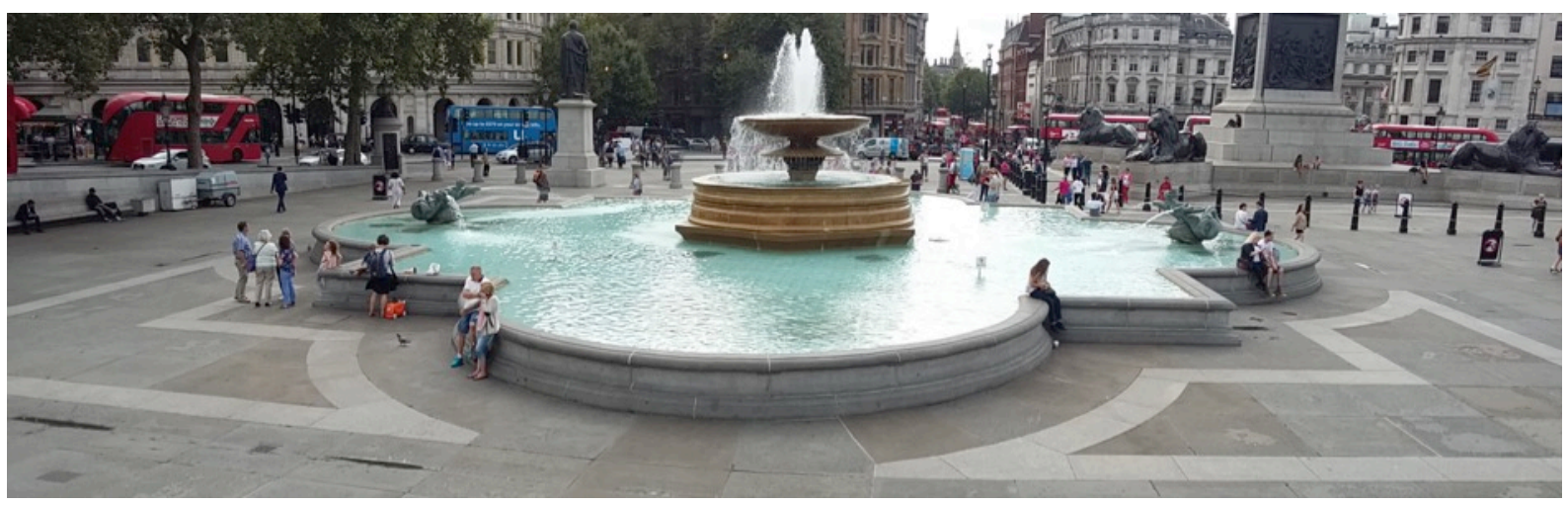

Figure 2. Trafalgar Square fountain, London: the non-playful design of a traditional water feature.

In the last decades, the emerging use of situated technologies has helped to bring whole new modes of social interaction and bodily engagement to urban spaces. And, in some cases, water has played a central role in encouraging these new social, spatial and experiential dynamics. One of these examples is the installation by Carlo Ratti Associati, built at the entrance of the 2008 Expo in Zaragoza, the Digital Water pavilion, an interactive structure of digitally controlled water curtains. Supported by digital technologies, these interactive interfaces are operating a significant change in the place and role of water fountains - from monuments to look at to structures to play with. 
However, with the rapidly growing field of media and interactive art and its implementation within the urban context, many aspects relating to people's engagement with these new types of installations are not well understood. Using our case studies of the Appearing Rooms and the Mirror Pool as examples, we propose to build on this body of work and explore in depth an approach to mediated urban environments that focuses on spatial layout and whole-body interactions, allowing us to unpack significant socio-spatial implications of whole-body interactions in specific urban settings featuring urban media installations. Specifically, we discuss how designers and artists are deploying digital technologies to reinterpret the typology of urban fountains and, in so doing, they turn traditional contemplative fountains into playful and multi-layered platforms for bodily interactions and social encounters. We draw particular attention to the material and experiential qualities of water-based interactions which are, in our view, two intertwined factors that help explain the long-standing popularity of urban water fountains.

Building on Lefebvre's concepts of "lived space" and "conceived space" outlined previously, the discussion of the Appearing Rooms and the Mirror Pool will also serve to illustrate how emerging digital technologies may be effectively used to foster active play in favour of liveable places - thus reconciling the conceived with the lived spaces, an outcome not easily attained by initiatives in this field.

\section{Methodology}

In this section we describe the initial exploratory studies that underpinned the selection of the two projects - the Appearing Rooms and the Mirror Pool - before proceeding with a description of the data collection process for each of the two projects.

\section{Exploratory Studies}

The initial stage of our research consisted in a series of exploratory and observational studies of contemporary urban splash facilities, most of which located in London. Our primary interest at this stage was in surveying the overall environment and developing our first impressions on how the use of water features supported by digital technologies could bring about a variety of playful behaviours as well as shared experiences to specific urban settings. We were especially drawn to splash facilities featuring creative, interactive and fully accessible water features that encouraged a close bodily contact with the water. Over the course of one month, one of the researchers visited, observed and made a preliminary selection of the most relevant urban splash facilities, according to the research criteria outlined above. Altogether, nine splash facilities - spanning a wide range of sizes and technological sophistication - were selected, eight of which in London and one located in Bradford, England. These splash facilities are classified in Table 1 according to their main spatial and playful characteristics.

\begin{tabular}{|c|c|c|c|c|c|c|}
\hline & \multicolumn{4}{|c|}{ SPATIAL PROPERTIES } & \multicolumn{2}{|c|}{ PLAYFUL PROPERTIES } \\
\hline $\begin{array}{l}\text { SPLASH } \\
\text { FACILITY }\end{array}$ & LOCATION & $\begin{array}{c}\text { AREA } \\
\text { (approx.) }\end{array}$ & $\begin{array}{c}\text { SHAPE OF } \\
\text { THE } \\
\text { WATER } \\
\text { FEATURE }\end{array}$ & SPATIAL SETTING & $\begin{array}{l}\text { INTERFACE } \\
\text { BEHAVIOUR }\end{array}$ & $\begin{array}{c}\text { KEY } \\
\text { PLAYFUL } \\
\text { ELEMENTS }\end{array}$ \\
\hline $\begin{array}{l}\text { Appearing } \\
\text { Rooms }\end{array}$ & $\begin{array}{l}\text { Southbank } \\
\text { Centre }\end{array}$ & $50 \mathrm{~m} 2$ & Square & $\begin{array}{l}\text { Calm, empty open } \\
\text { space used as a } \\
\text { crossing site amid } \\
\text { cultural/ leisure } \\
\text { buildings; low } \\
\text { pedestrian traffic }\end{array}$ & $\begin{array}{l}\text { Watery walls } \\
\text { come up and } \\
\text { down defining } \\
\text { "rooms" }\end{array}$ & $\begin{array}{l}\text { Enter and leave } \\
\text { the inner spaces } \\
\text { of the fountain } \\
\text { without getting } \\
\text { wet }\end{array}$ \\
\hline $\begin{array}{l}\text { Edmond J. } \\
\text { Safra } \\
\text { Fountain }\end{array}$ & $\begin{array}{l}\text { Westminster } \\
\text { (Somerset } \\
\text { House) }\end{array}$ & $750 \mathrm{~m} 2$ & $\begin{array}{l}\text { Rectangular } \\
\text { grid }\end{array}$ & $\begin{array}{l}\text { Monumental courtyard } \\
\text { of a major cultural } \\
\text { venue; segregated from } \\
\text { streets; low traffic of } \\
\text { crossing visitors/ } \\
\text { workers }\end{array}$ & $\begin{array}{l}\text { Jets randomly } \\
\text { appear and } \\
\text { disappear at } \\
\text { varying heights }\end{array}$ & $\begin{array}{l}\text { Wander over the } \\
\text { fountain while } \\
\text { trying to predict } \\
\text { what will happen } \\
\text { next }\end{array}$ \\
\hline $\begin{array}{l}\text { Granary } \\
\text { Square }\end{array}$ & Kings Cross & $400 \mathrm{~m} 2$ & $\begin{array}{c}\text { Four } \\
\text { rectangular } \\
\text { grids }\end{array}$ & $\begin{array}{l}\text { Broad, scenic } \\
\text { canalside plaza; } \\
\text { crossing area amid } \\
\text { mixed neighbour- } \\
\text { hood; steady flow of } \\
\text { diverse communities }\end{array}$ & $\begin{array}{l}\text { Animated jets, } \\
\text { fog, app-based } \\
\text { game; } 1,080 \\
\text { LED-lit jets }\end{array}$ & $\begin{array}{l}\text { Move around } \\
\text { and follow the } \\
\text { animated jets; } \\
\text { use the mobile } \\
\text { app to control } \\
\text { the direction of } \\
\text { the jets (at } \\
\text { scheduled times } \\
\text { only) }\end{array}$ \\
\hline $\begin{array}{c}\text { Merchant } \\
\text { Square Water } \\
\text { Maze }\end{array}$ & Paddington & $130 \mathrm{~m} 2$ & Circular & $\begin{array}{l}\text { Tranquil canalside } \\
\text { thoroughfare in mostly } \\
\text { residential area; low } \\
\text { traffic of pedestrians }\end{array}$ & $\begin{array}{l}\text { Groups of jets } \\
\text { come up and } \\
\text { down in a maze } \\
\text { formation }\end{array}$ & $\begin{array}{l}\text { Move across the } \\
\text { water maze; } \\
\text { traverse the }\end{array}$ \\
\hline
\end{tabular}




\begin{tabular}{|c|c|c|c|c|c|c|}
\hline & & & & & & $\begin{array}{l}\text { fountain without } \\
\text { getting wet }\end{array}$ \\
\hline Mirror Pool & $\begin{array}{c}\text { City Park } \\
\text { (Bradford, } \\
\text { UK) }\end{array}$ & $3,400 \mathrm{~m} 2$ & Oval & $\begin{array}{l}\text { Massive scenic plaza } \\
\text { in town } \\
\text { centre; mixed-use } \\
\text { neighbour-hood; } \\
\text { transitional, } \\
\text { integrated } \\
\text { character } \\
\text { (crossing/staying) }\end{array}$ & $\begin{array}{l}\text { Reflection pool, } \\
\text { fog, animated } \\
\text { jets, geysers, } \\
\text { 30m high water } \\
\text { cannon; LED-lit } \\
\text { jets }\end{array}$ & $\begin{array}{l}\text { Walk around } \\
\text { the various jets; } \\
\text { get close and } \\
\text { feel the fog and } \\
\text { geyser effects; } \\
\text { move across the } \\
\text { pool or its } \\
\text { causeways }\end{array}$ \\
\hline $\begin{array}{l}\text { More London } \\
\text { Riverside } \\
\text { Fountains }\end{array}$ & $\begin{array}{l}\text { Southwark } \\
\text { (City Hall) }\end{array}$ & $300 \mathrm{~m} 2$ & $\begin{array}{c}\text { Four linear } \\
\text { banks }\end{array}$ & $\begin{array}{l}\text { Partly segregated } \\
\text { riverside area affording } \\
\text { broad views; offices } \\
\text { and shops nearby; high } \\
\text { levels of pedestrian } \\
\text { flows }\end{array}$ & $\begin{array}{l}\text { Groups of } 200+ \\
\text { jets appear and } \\
\text { disappear }\end{array}$ & $\begin{array}{l}\text { Move across the } \\
\text { fountain while } \\
\text { trying to predict } \\
\text { which jets will } \\
\text { appear and } \\
\text { disappear }\end{array}$ \\
\hline $\begin{array}{l}\text { Peninsula } \\
\text { Square } \\
\text { Fountains }\end{array}$ & $\begin{array}{l}\text { Greenwich } \\
\text { (O2 Arena) }\end{array}$ & $240 \mathrm{~m} 2$ & $\begin{array}{l}\text { Three } \\
\text { circular } \\
\text { pools }\end{array}$ & $\begin{array}{l}\text { Vast open space by the } \\
\text { entrance to a major } \\
\text { music venue; occasional } \\
\text { static activities and } \\
\text { irregular pedestrian } \\
\text { flows }\end{array}$ & $\begin{array}{l}\text { Fog, geysers, lit } \\
\text { jets }\end{array}$ & $\begin{array}{l}\text { Get close and } \\
\text { feel the jets, fog } \\
\text { and geyser } \\
\text { effects }\end{array}$ \\
\hline $\begin{array}{l}\text { Princess } \\
\text { Diana } \\
\text { Memorial } \\
\text { Fountain }\end{array}$ & $\begin{array}{l}\text { Knightsbridge } \\
\text { (Hyde Park) }\end{array}$ & $700 \mathrm{~m} 2$ & Oval & $\begin{array}{l}\text { Calm, picturesque area } \\
\text { segregated in a vast } \\
\text { central park; } \\
\text { no crossing traffic; } \\
\text { fenced site devoid of } \\
\text { urban facilities }\end{array}$ & $\begin{array}{l}\text { Cascading, } \\
\text { bubbling stream } \\
\text { runs through a } \\
\text { stone ring }\end{array}$ & $\begin{array}{l}\text { Walk along the } \\
\text { watery pathway } \\
\text { or sit on its } \\
\text { borders to feel } \\
\text { the stream }\end{array}$ \\
\hline $\begin{array}{l}\text { The Water } \\
\text { Labyrinth }\end{array}$ & $\begin{array}{c}\text { Stratford } \\
\text { (Olympic } \\
\text { Park) }\end{array}$ & $350 \mathrm{~m} 2$ & $\begin{array}{l}\text { Winding } \\
\text { ribbon }\end{array}$ & $\begin{array}{l}\text { Large plaza next to a } \\
\text { scenic walkway amid } \\
\text { sports \& leisure } \\
\text { facilities; mid-to-low } \\
\text { pedestrian flows; } \\
\text { segregated from streets }\end{array}$ & $\begin{array}{l}195 \text { LED-lit jets } \\
\text { spring in varying } \\
\text { sequences and } \\
\text { heights }\end{array}$ & $\begin{array}{l}\text { Race through the } \\
\text { line of jets } \\
\text { (following them } \\
\text { to get wet or } \\
\text { avoiding them to } \\
\text { stay dry) }\end{array}$ \\
\hline
\end{tabular}

Table 1. Spatial and playful properties of the splash facilities surveyed in the initial stages of the research. By "interface" (sixth column) we mean the design features that drive the interactions. The text in bold indicates the two case studies of this paper (the Appearing Rooms and the Mirror Pool) as well as the Granary Square fountains, another pivotal project for our discussion.

Following this preliminary selection, one of the researchers undertook systematic fieldwork in each splash facility. The principal methods of data collection at this stage are qualitative, non-participant observations, field notes, photographs and particularly the recourse to time-lapse photography. For this initial approach, the researcher applied the same protocol in all splash facilities: to avoid interfering with the spontaneous behaviours around the water features, the researcher stood in a secluded, inconspicuous position at all times, and used a small action camera, which was set to take photographs of the interactions at regular intervals of 30 seconds. These series of time-lapse photographs were then assembled into videos for further analyses.

This observational approach required a detached posture not to disturb people's natural behaviours and hence maximise the ecological validity of the study. Nonetheless, another crucial part of the research motivation was in understanding what it is like and how it feels to play with the water features; this involves an "experiential bodily knowing" - a knowing how whose meaning is produced in and through movement (Larssen et al. 2007; Levisohn \& Schiphorst 2011), and therefore can only be achieved through the first-hand experience of the water features and the urban setting immediately around them. In practical terms, this meant leaving the secluded position after the data collection was completed - leaving the role of detached observer - and taking part in the interactions on the splash facilities.

The first-hand experience of all splash facilities surveyed in this exploratory fieldwork, coupled with the analysis of the material collected at their locations (as indicated on Table 1), informed a reflection upon their significance and potential for further exploration, in light of our research questions and motivations. At the end of this stage, we selected two water features - the Appearing Rooms, in London, and the Mirror Pool, in Bradford - for a more comprehensive study. The selection of these water features was based on three main reasons:

1. Both are fixed interfaces, embedded in their urban surroundings - the Appearing Rooms is semi-permanent (activated every year during the summer), and the Mirror Pool is a permanent urban facility. 
2. The broader "social appeal" of playfulness - the water features we observed in both the Appearing Rooms and in the Mirror Pool were actively played with by a varied population of different age groups, and not only by children, as observed in the other splash facilities surveyed. These broader levels of explicit social participation through play allow us to look deeper into the relationships between playfulness, bodily interactions and social encounters mediated by digital technologies.

3. The urban setting of the projects - the spatial surroundings of the Appearing Rooms and the Mirror Pool are characterised by a rich and diverse flow of people and social encounters. From an urban point of view, both projects occupy a privileged position, being set in highly accessible and visible areas of their cities; in Space Syntax terms, their locations are highly integrated into the spatial network of their urban fabric (Hillier and Hanson 1984). Other splash facilities that were surveyed, albeit featuring very creative designs and playful water choreographies, suffer from spatial segregation, that is, they are more or less detached from the core spaces of social activity in their urban neighbourhoods, the spaces which most people use on an everyday basis. The Princess Diana Memorial Fountain, for example, occupies a large, scenic yet secluded area in Hyde Park, hundreds of metres away from the main pedestrian routes of Central London. A similar situation is observed in the Somerset House fountain, set at the centre of a monumental courtyard, enveloped by the grand architecture of the cultural venue and detached from the bustling main streets further away. In contrast, the highly integrated urban locations of the Appearing Rooms and the Mirror Pool better respond to our objectives of finding out the social and spatial implications of smart playful technologies in the lived experience of contemporary cities.

\section{Case Studies - Data Collection}

The case studies of the Appearing Rooms and the Mirror Pool were conducted following a longitudinal approach, which involved visiting and collecting data at the study sites over an extended period of time. The fieldworks were concentrated in the summers of 2015 and 2016 (Appearing Rooms), and from 2016 to 2017 (Mirror Pool). In both cases, one of the researchers collected data at different times of the day, on different days of the week, and in different seasons of the year, so as to enhance the ecological validity of the studies. Apart from these commonalities, some aspects of the data collection process were adapted to the specific circumstances of each project, as described in the following sections.

\section{The Appearing Rooms}

Over the course of three years, observations, notes and photographs of the installation site were collected and analysed, both in the winter season - when the Appearing Rooms was not installed - and especially in the summer, when the installation was running. In the latter case, the data collection took place in August and September of 2015 and 2016, in which period time-lapse photography was employed (in addition to the aforementioned methods) to capture the urban context and the various interactions taking place both within the Appearing Rooms and in the immediate surroundings of the installation. The sessions of time-lapse photography lasted a minimum of 30 minutes and employed a small action camera, which was set to take photographs at regular intervals of 30 seconds. Eventually, the series of still images captured on each session were assembled into time-lapse videos.

The data collection was primarily conducted from the Level 5 balcony of the Royal Festival Hall, a high and inconspicuous position affording bird's-eye views of the study site - the Riverside Terrace - and its neighbourhoods. This position matched the large-scale, complex and dynamic setting of the Southbank Centre, which called for an expanded perspective, wide enough to observe and capture not only the site of the Appearing Rooms, but also its broader urban context.

\section{Mirror Pool}

Since the Mirror Pool is a permanent urban facility, the fieldworks were distributed across various seasons, from November 2016 to November 2017. This was an important methodological decision because the use of open, outdoor spaces like the Mirror Pool is highly contingent on factors like temperature, rain, wind and light conditions - and one of the core objectives of our study is to clarify whether, and to what extent, the interactive and playful features of the Mirror Pool were able to attract and retain people under different weather conditions.

Altogether, the data collection of the Mirror Pool involved 33 recording sessions using time-lapse photography, following the same methodological procedure adopted in the study of The Appearing Rooms. In addition to timelapse photography, field notes and high-resolution photographs were also used throughout the study as subsidiary methods, especially to record fleeting, unusual and/or revealing moments of interactions in the Mirror Pool. Two opposite locations overlooking the Mirror Pool were used at different times to position the camera and to observe the social activities: the terrace on the roof of The Pavilion Café (in the southern approach to the City Park) and the third floor of the City Hall building, in the north side of the park. 


\section{Case studies - Analysis}

This section presents the two case studies separately, following the same order: we begin by outlining the urban context of each project, then we zoom in and describe its interactive and playful elements, followed by the results of each case study.

\section{Case Study I: The Appearing Rooms}

\section{Urban context}

The installation Appearing Rooms is located in the Southbank Centre, a major complex of artistic and cultural venues in Central London. The installation occupies a prominent area of the Southbank Centre, known as the Riverside Terrace - a broad, continuous, open area overlooking the river Thames and stretching alongside the principal landmarks of the Southbank Centre: two performance venues (the Royal Festival Hall and the Queen Elizabeth Hall) and an art gallery (the Hayward Gallery). This central position of the Riverside Terrace, in addition to the various connections it offers for pedestrian circulation, makes the installation site a highly used urban space on an everyday basis.

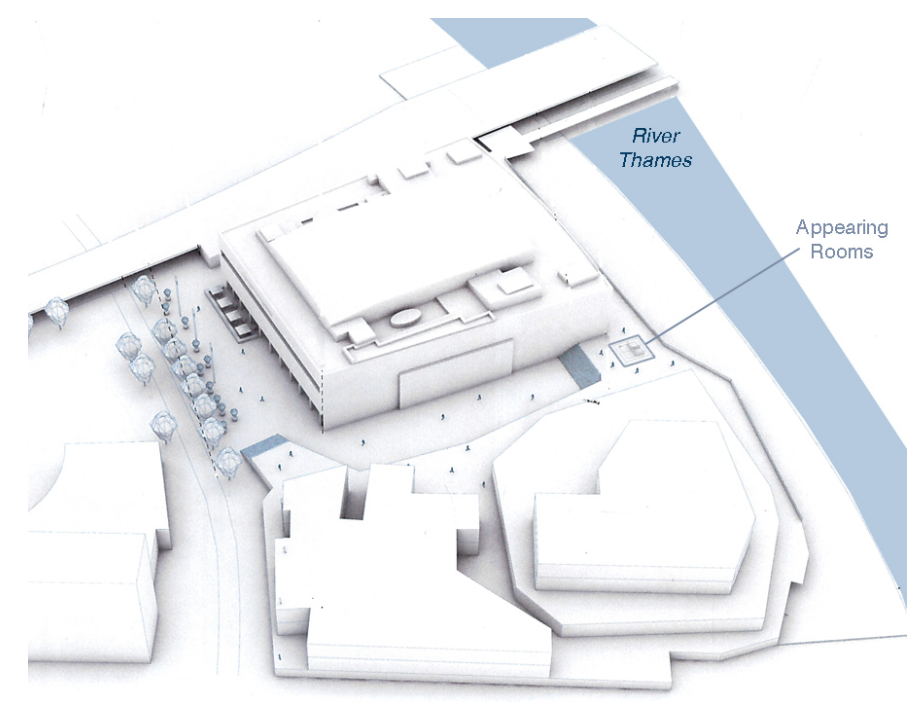

Figure 3. Urban context of the Appearing Rooms: perspective of the Southbank Centre with the Royal Festival Hall on the top, the Hayward Gallery on the bottom left and the Queen Elizabeth Hall on the bottom right. Image adapted from Ivers 2018 (with permission).

In normal conditions, i.e. when the installation Appearing Rooms is not present, or it is switched off, the study site does not offer many props or facilities for people to stay or socialize. These are limited to a few concrete benches and wooden tables placed at the borders of the study site, where, in mild and warm days, some people can be observed engaged in activities like chatting, smoking, reading, using the mobile phone, taking a nap or simply sunbathing. Apart from these benches and tables, the study site stands as an empty outdoor space; an area in which, on an everyday basis - and especially during cold seasons - static activities or social encounters are rather low and incidental.

\section{Project Overview}

The Appearing Rooms is an installation that has participated in several exhibitions across the world since 2004. In London, the Appearing Rooms has been installed every summer since 2007, at the same site in Southbank Centre, as part of the annual Summer Festival. Designed by Danish artist Jeppe Hein, the Appearing Rooms is a water-based interactive installation with a dynamic character. The artwork consists of four inner spaces - the "rooms" - that seem to constantly appear and disappear as a series of computer-programmed, 2.30-metre-high water jets come up and down (Hein 2019). 

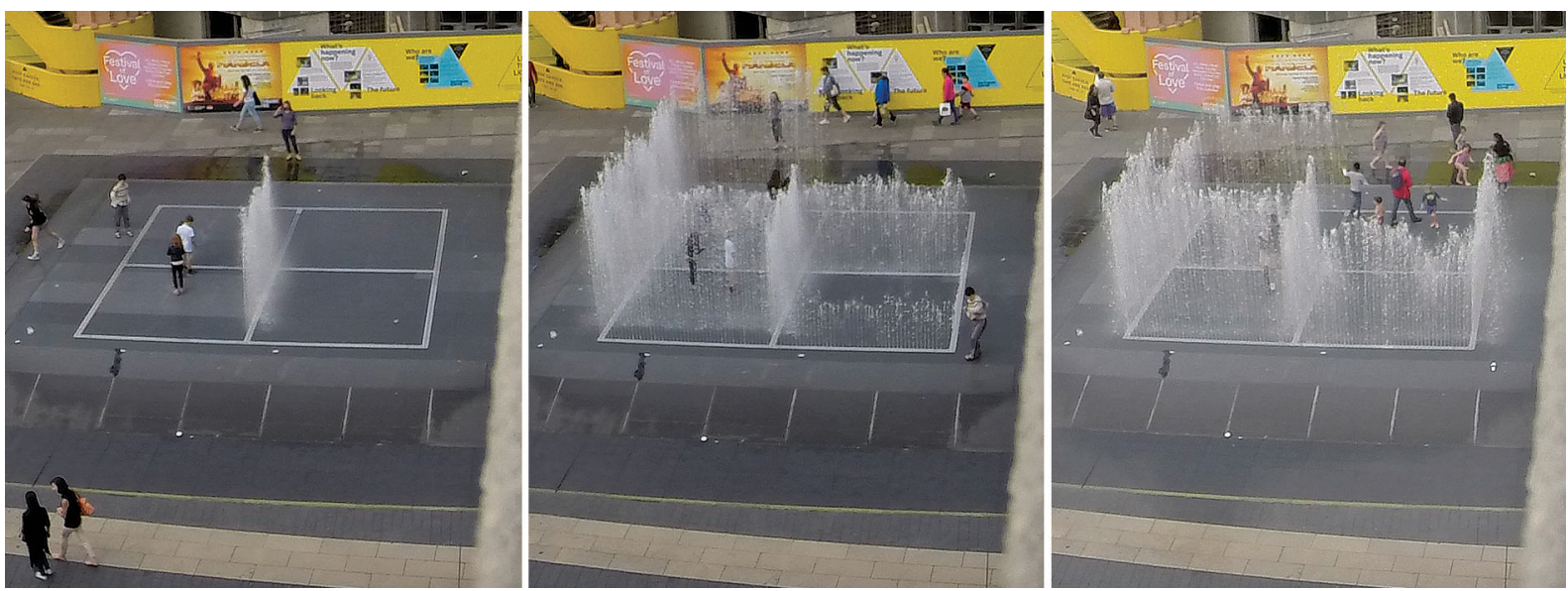

Figure 4. Sequence of pictures showing people's interactions and the behaviour of the Appearing Rooms. Each one of

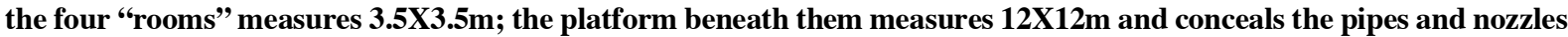
of the installation, while the computing machinery that gives life to the installation is stored in a metallic shed, located beside the platform (not shown in the pictures).

At regular intervals of ten seconds, the water choreography changes in some parts of the installation; yet such changes do not respect a clear or predictable sequence and, as a result, players can only guess which water jets will raise and which will fall within the next few seconds. The visual effect is that of watery walls coming up and down, defining inner spaces that become momentarily more or less accessible. From an interactional perspective, the Appearing Rooms can be described as a challenging "water pavilion" or "aquatic sculpture", in which the interactions are mainly driven by surprise, risk and chance. In fact, the key playful character of the installation consists in encouraging people to enter, to move across and to leave the "appearing rooms" without getting wet. Being trapped inside one of the "rooms" or soaking parts of the body while moving in or out of the installation is all part of the playful experience proposed by the artist.

\section{Results}

We begin by presenting the results of a macro-scale socio-spatial analysis of the installation site. Firstly, we observed and mapped the pedestrian flows in the Riverside Terrace when the Appearing Rooms was installed and operating. Two main axis of circulation were identified: the first across the full extension of the terrace, running parallel to the main facade of the Royal Festival Hall (i.e. the facade facing the river); and the second axis perpendicular to the first one, stretching through the adjoining area known as Festival Terrace, adjacent to the south-western facade of the Royal Festival Hall (Figure 5). These main routes of pedestrian circulation remained the same after the removal of the Appearing Rooms. The changes we observed, in this case, were related to the secondary, less used routes, since the installation functioned as a target point or a temporary destination, introducing additional local-scale pedestrian flows (flows of short-range towards the installation) that would disappear in ordinary conditions (Figure 5 , right).

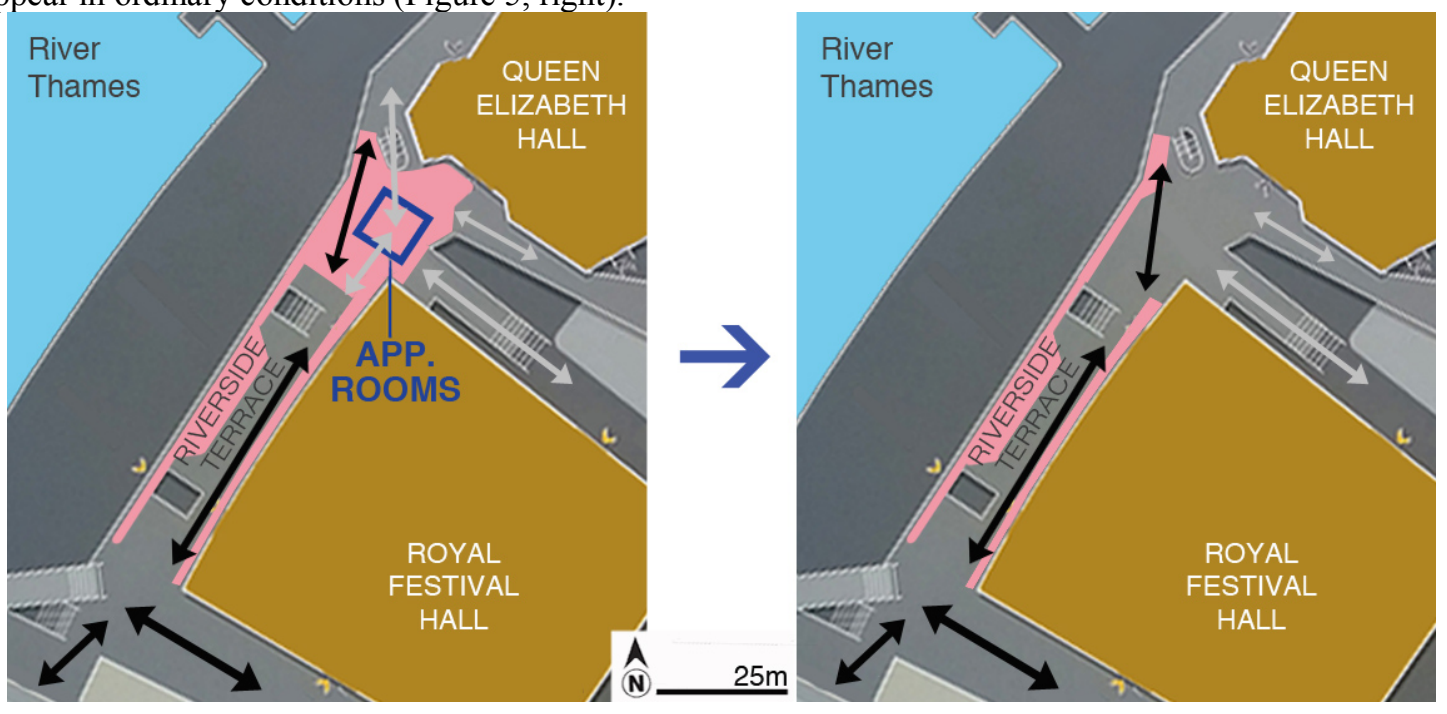

Figure 5. Pedestrian flows and main zones of stationary activities in the Riverside Terrace with (left image) and without the Appearing Rooms (right image). The blue rectangle in the left image represents the position and approximate size of the installation. The arrows indicate the pedestrian flows in the area: black arrows for main flows and grey arrows for secondary flows. The pink shaded areas represent the main zones occupied by stationary activities. 
Looking at the stationary activities, we mapped three main zones of occupation: the spatial vicinities of the installation Appearing Rooms; the narrow linear space adjacent to the main facade of the Royal Festival Hall; and the space that includes the central area of the Riverside Terrace and extends alongside its north-western border (Figure 5, left). Once the installation was removed, the only noticeable change in the spatial distribution of static activities occurred on the area formerly occupied by the installation (Figure 5, right). This is unsurprising: as explained earlier, that part of the Riverside Terrace lacks further facilities for people to stay or socialize (apart from a few concrete benches and tables placed at the border). Yet, such benches and tables would still attract occasional static activities throughout the year, even in the cold seasons - for example at times when the sun reached the benches.

Zooming in to the micro-scale aspects of the interactions, the case study reveals that the playful and bodily interactions with the Appearing Rooms is as much about space as it is about time: as people approach the installation, they feel enticed to observe the water jets' dynamic behaviour from the outside, for at least a few seconds. The ten-second timing of the water choreography gives the installation a sense of vitality while encouraging people to take quick decisions: spectators (Reeves 2011) should decide between stepping forward to join the inner rooms (and becoming players) or to keep watching the interactions from the outside (and stay as spectators). Here, spectating represents an interactional activity; which is, continuously ordered and temporally coordinated (Tekin and Reeves 2017), where spectators potentially support players with continuous 'scaffolding'; critique players techniques during and between moments of play; or recognize and praise competent players conduct; likewise, players (O'Hara et al. 2008) should decide between staying in their specific position within the installation, moving to another "room" or leaving the play area. Failing to synchronising one's movements to the set pace of the watery walls often results in players being "hit" by a fair amount of cold water that will certainly soak their clothes and shoes. For children players this situation is easier to cope with, as many of them were observed in swimwear around the installation area - which indicates that numerous families were acquainted with the Appearing Rooms and made a planned visit to the site. For teenagers and adult players, on the contrary, who were observed engaging with the installation wearing everyday clothes - some of them in suits and carrying bags or backpacks - the ever immediate risk of missing the timing of the watery walls and soaking themselves seems to furnish their experience with an extra amount of thrill.

Such sense of challenge and thrill has long been described by literature as vertigo, one of the key typologies of play, originally classified by Roger Caillois in the 1960s (Caillois 2001) and further discussed in the context of playful activities in urban spaces by Quentin Stevens (2007). Vertigo relates to the pursuit of a "special disorder or sudden panic" (Caillois 2001, p. 26); the deliberate escape from normal bodily experiences and self-control, which "negates instrumental benefit and embraces risk for its own sake and the affirmation of human bodily experience" (Stevens 2007, p. 43). Common actions and behaviours observed among players in the Appearing Rooms, such as laughing, shouting and hesitating as to which direction to move, all reflect the vertiginous character of the interactions with the installation. The design of the Appearing Rooms explores time as the basis for vertigo: time, in this case, is the pressing element that calls players to immediate action, in response to the ever-changing spatial configuration of the appearing and disappearing rooms.

Arguably, the social gathering observed around the Appearing Rooms, as shown in Figure 6, would also take place if the fountain's behaviour were not digitally controlled. The mere presence and easy access to clear water jets situated in an open, outdoor urban space - especially on a sunny, warm day - is certainly a powerful attractor in itself of passers-by and visitors to the area. Furthermore, the architectural and urban qualities of the Riverside Terrace, site of the Appearing Rooms, helps to create an atmosphere of livelihood and relaxation, suitable for social encounters. The site is large enough to accommodate numerous visitors at once, and people are free to choose where to stay, how to settle their bodies (e.g., sitting on the floor, leaning against the railings or simply standing), and how to group themselves, since the space is flat, fully pedestrianized and mostly devoid of urban furniture. In fact, the site of the Appearing Rooms provides a micro version of an urban beach: apart from the water squirting on the fountain itself, this character is reinforced by the cultural buzz and the leisure facilities spread across the premises (the Southbank Centre), in addition to the panoramic vistas of the flowing waters of the river Thames. 


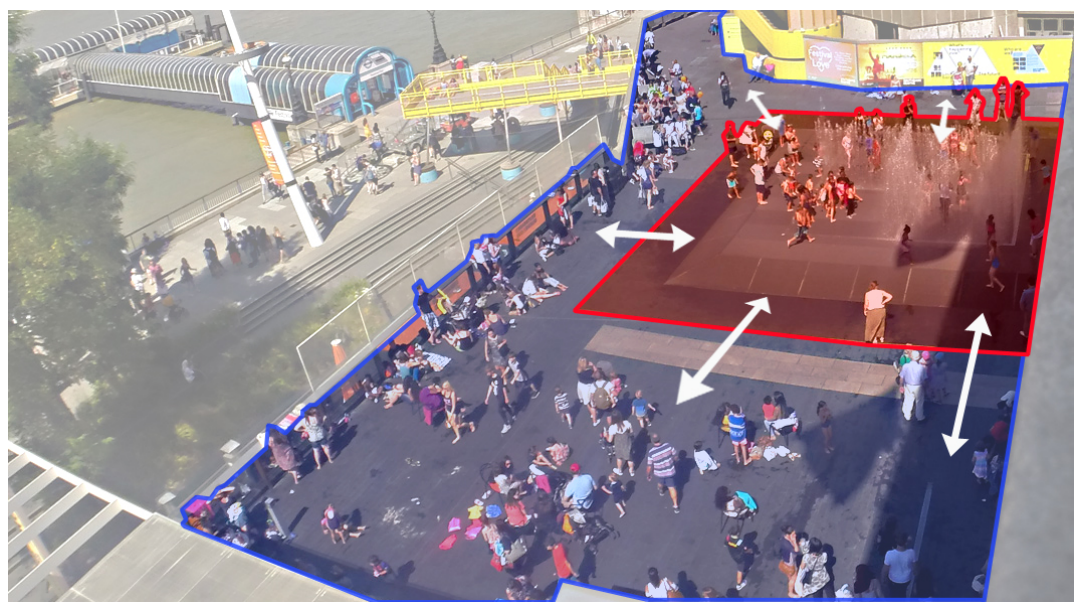

Figure 6. Social encounters around the Appearing Rooms. The installation area (highlighted in red) is primarily used by players engaged in whole-body interactions with the water features, while the surroundings of the installation (highlighted in blue) are mainly occupied by people engaged in other activities, like observing, waiting, photographing, and chatting.

In spite of the aspects outlined above, our observations found that, in the case of the Appearing Rooms, the recourse to digital technology does make a difference in the way the fountain is approached and experienced. The computercontrolled random movements of the water jets create a sense of surprise and unpredictability that is fundamental in attracting passers-by and making them stop, observe and potentially play with the fountain. This unpredictable character of the fountain is especially important to attract adults, who are not as predisposed as children to engage with flowing water in urban spaces, as our initial exploratory studies of splash facilities revealed (Table 1).

From an urban and social perspective, our study also revealed that the digitally controlled behaviour of the Appearing Rooms is equally important, because the bodily, social and playful interactions observed within the fountain usually sparked other forms of interactions, social encounters and playfulness in the space around the fountain. For example, we frequently observed passers-by stopping in the vicinities of the Appearing Rooms after noticing other people playing with the fountain. The presence of these spectators usually attracted more people to the area, causing the so-called "honey pot effect" (Fischer and Hornecker 2012). Once spectators gathered in the surroundings of the fountain, various types of interactions and encounters took place; these included: photographing or filming the fountain, talking to other people, observing people playing, walking around the fountain and stepping on the Appearing Rooms to play (Figure 7).

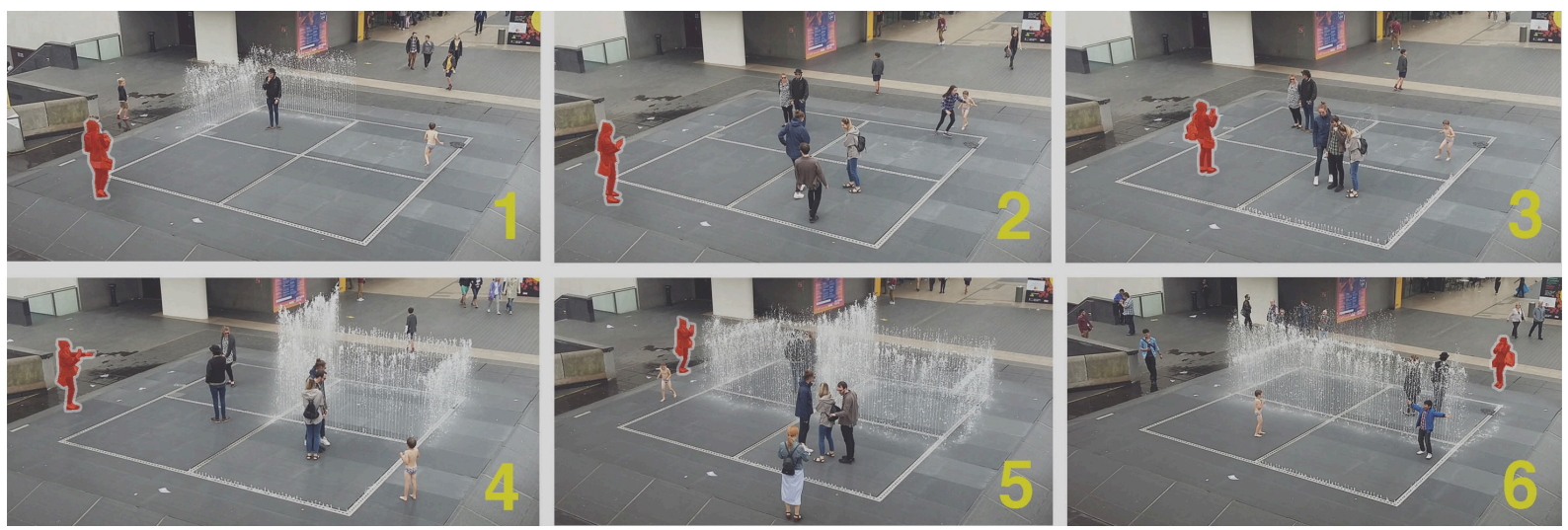

Figure 7. A sequence of playful and social interactions in the Appearing Rooms: a group of friends play with the fountain, moving into different "rooms", while another member of the group (highlighted in red) photograph their experience from different positions on and around the fountain.

\section{Case Study II: The Mirror Pool}

\section{Urban context}

The water feature known as "Mirror Pool" is the centrepiece of the City Park, a large-scale project of urban regeneration situated in central Bradford, UK, which opened to the public in 2012. Costing £24.4 million, the project of the City Park was intended to be a "catalyst for regeneration", a milestone initiative aimed at boosting the economy of Bradford, fostering the civic pride and restoring a sense of belonging to its inhabitants (Barker et al. 2014). The City Park occupies a historically significant area in the centre of Bradford, home to the Grade I listed Victorian building of the City Hall. 


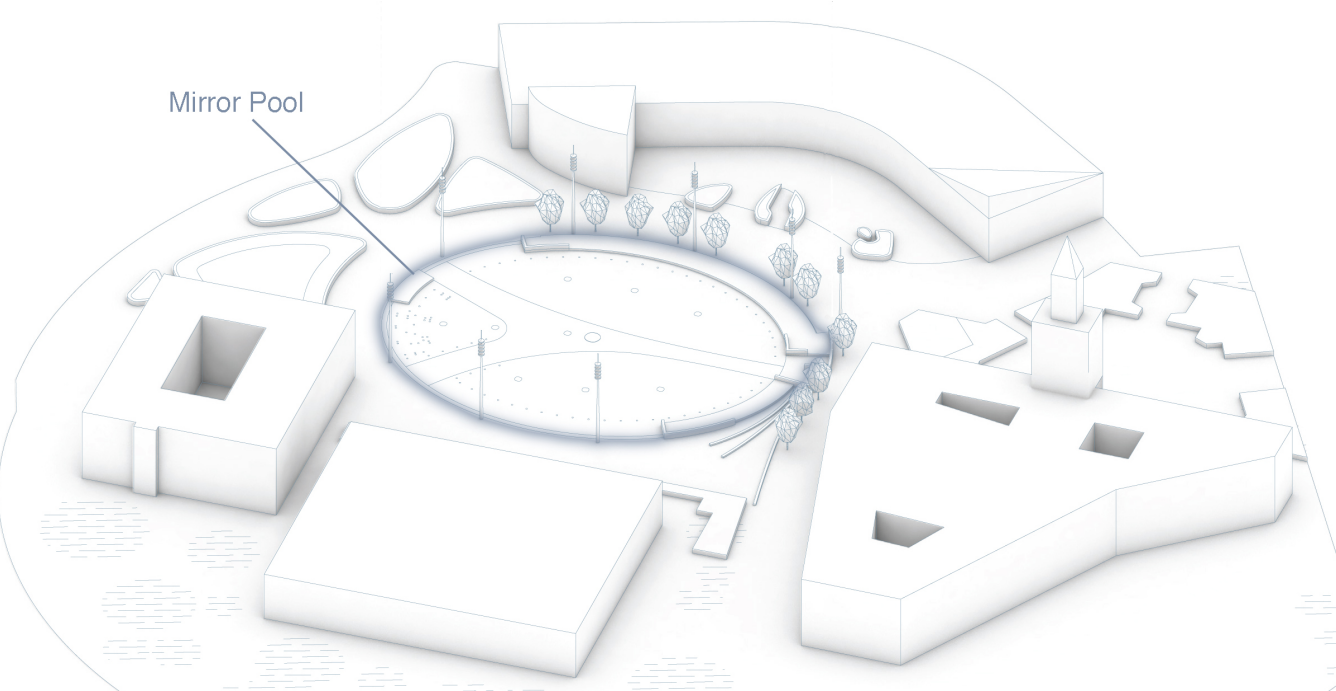

Figure 8. Urban context of the Mirror Pool: perspective of Bradford's City Park with the City Hall building on the right, the commercial centre on the top and the Magistrate's Court on the bottom. Image adapted from Ivers 2018 (with permission).

From an urban perspective, the City Park sits in a focal point which links together a diverse commercial area, a cultural and educational neighbourhood, and a major transport hub. From a spatial standpoint, such urban position gives the City Park area a transitional character, a place where people coming and going from the mixed neighbouring areas pass through and meet each other. Apart from these passing pedestrians, the area also attracts a steady number of people who come to work on or visit the urban facilities at the City Park - especially the City Hall, the Magistrates' Court, the local library and a few eateries concentrated in the North side of the park.

\section{Project Overview}

The Mirror Pool is a project jointly designed by the teams of The Fountains Workshop, Gillespies, Haque Design + Research and the artist Wolfgang Buttress. It consists of three independent pools whose geometrical arrangement, in addition to the coordinating behaviour of its water jets, define a single, dynamic interactive space, which is perceived and experienced as a coherent whole. Two elliptical pools are symmetrically positioned in the north and south portions of the area, while the third pool, triangular and smaller than the others, is located at the west (Figure 9). In technical terms, each one of the three pools constitutes a splash pad in itself: three separate tanks supply and collect the water flowing on each pool, while the system allows the water effects within each pool to be controlled independently. Normally, though, the animations of the water jets are programmed to operate in concert across all three pools, reinforcing the sense of unity of the Mirror Pool.

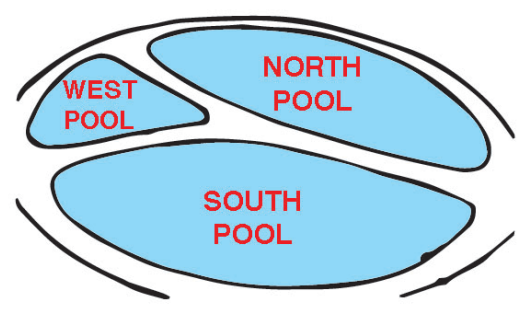

Figure 9. The Mirror Pool's three independent pools.

Three pre-programmed modes define the water level on each pool at any time: the "drain" mode, which, as the name indicates, drains all the water and transforms the pool's space into a dry plaza; the "partial" mode, which limits the water to puddles around the fountains; and the "full" mode, which floods the entire surface of the pool. Distinct spaces and affordances arise from these modes; the "drain" mode operates daily, from midnight to 7.00am, in order to save power, allow for routine cleaning and maintenance, and also to make room for the especially commissioned urban media artwork Another Life (Haque Design + Research 2012) - dynamic and interactive laser lights projected on the floor of the site every night (Figure 10, right). The "drain" mode is also enabled when the space of the Mirror Pool hosts special events, such as Christmas and civic celebrations, performance festivals and fairs. The "partial" mode can be set to varying levels, from small puddles concentrated alongside the edges of the pool, leaving a broad dry surface that can be used as a crossing area, to large ponds covering most of the pool and defining narrow causeways. The name Mirror Pool stems from the visual effect sparked when the "full" mode is enabled in all three pools. As the water fills the 3,600 square metres of the fountains, the causeways gradually disappear and a continuous, urban-scale "watery mirror" takes over, reflecting the surrounding architecture and 
the sky. In spite of its massive dimensions, the Mirror Pool is a very shallow water feature, with a maximum depth of $25 \mathrm{~cm}$ that makes it a safe and accessible area, even for little children.
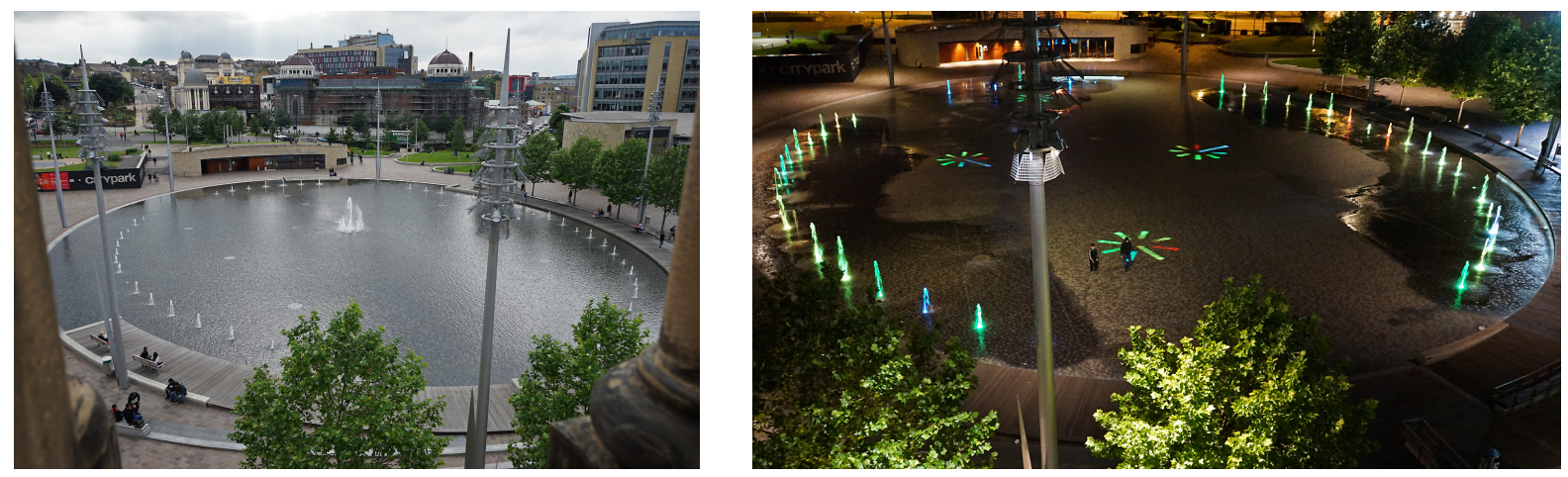

Figure 10. Day and night views: two markedly different configurations of the Mirror Pool, seen from the City Hall building: the full mode turning the space into a massive watery mirror (left), and the nocturnal dry mode with the dynamic laser projections and illuminated fountains (right).

The Mirror Pool also features a variety of fountains that are fitted with LED lights and can be observed in action at different times of the day. The most frequently operating fountains are the perimeter fountains (distributed around the edge of the Mirror Pool and programmed to run different choreographies); the play jets (low pressure, playful fountains especially suitable for children, situated in the west pool); and the arching jets (located between the south and west pools and forming a watery tunnel that playfully invites people to walk through). Other water effects of the Mirror Pool are activated less often, and are not usually seen on an everyday basis: the geysers (special fountains able to produce steam and fog effects) and the so-called Bradford Blast, a powerful central fountain capable of blasting water up to thirty metres in the air.
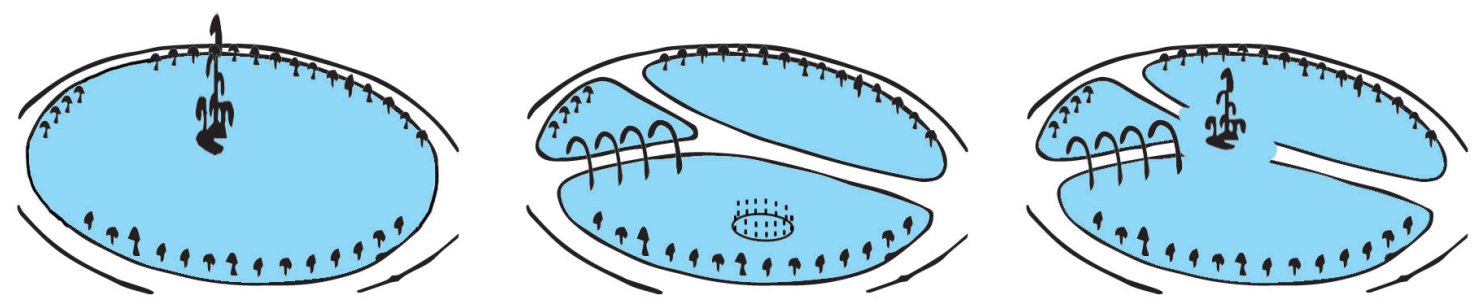

Figure 11. A few samples of the multiple layouts and water effects performed by the Mirror Pool. Left: the full mode with central and perimeter fountains and play jets; middle: the partial mode revealing clear causeways, with the arching jets and mist effect activated; right: the partial mode with the central fountain flooding part of the causeways.

The Mirror Pool can be described as an interactive space, both in a loose and in the more strict sense of the term "interactive". Firstly, because the water features and the surrounding built elements of the Mirror Pool encourage people to engage in different activities - or "interact" - either with the environment (for example by observing, sitting, relaxing or playing with the water jets), or with other people, for example by chatting or meeting friends or strangers. Secondly, the Mirror Pool also features some properly interactive technologies, if we take HCI's view of interaction as a process based on a feedback loop, whereby a user provides some sort of input to a system, which processes the information and then provides the person with an output, in a contingent, undetermined and dynamic process (Preece et al. 2002; Dubberly et al. 2009). Following this notion of interaction, the Mirror Pool features one of Europe's largest permanent interactive artworks, named "Another Life" and designed by the practice Haque Design + Research. The interactive features of the artwork Another Life include dynamic light projections on the water and ground of the Mirror Pool that respond to the movements of visitors. As the design team describes it:

We created a software engine and "urban operating system" that choreographs and coordinates the activity of
various elements within and around the pool, determining what happens when, and how the projections and
fountains respond to visitors. The system continually adjusts its outputs in response to various environmental
and infrared camera sensors, as well as external factors and community requirements [...]. Another Life gives
the City Park development an adaptive and distinctive 'personality', which changes over time and according to
varying conditions. The richness of the interactions (created by the choreographies and the sensors and outputs)
will gradually develop as visitors and the local community engage with the artwork over the course of several
years (Haque Design + Research 2012).

Results

This section begins with the results of our macro-scale socio-spatial analysis of Bradford's City Park, site of the Mirror Pool. Then we zoom in and look at the bodily, social and playful encounters that emerged within and immediately around the Mirror Pool. 
As outlined earlier, the City Park occupies a privileged position in central Bradford, connecting diverse neighbourhoods and communities. This favourable position is reflected on the high levels of pedestrian flows observed across the City Park. As shown in Figure 12, we identified a main axis of circulation stretching through the open space to the north of the Mirror Pool and extending towards the street crossings located at either sides of the City Park. The central and southern areas of the study site registered lower levels of pedestrian flows, and the same occurred at the spatial vicinities of the Mirror Pool (not including its northern surroundings).

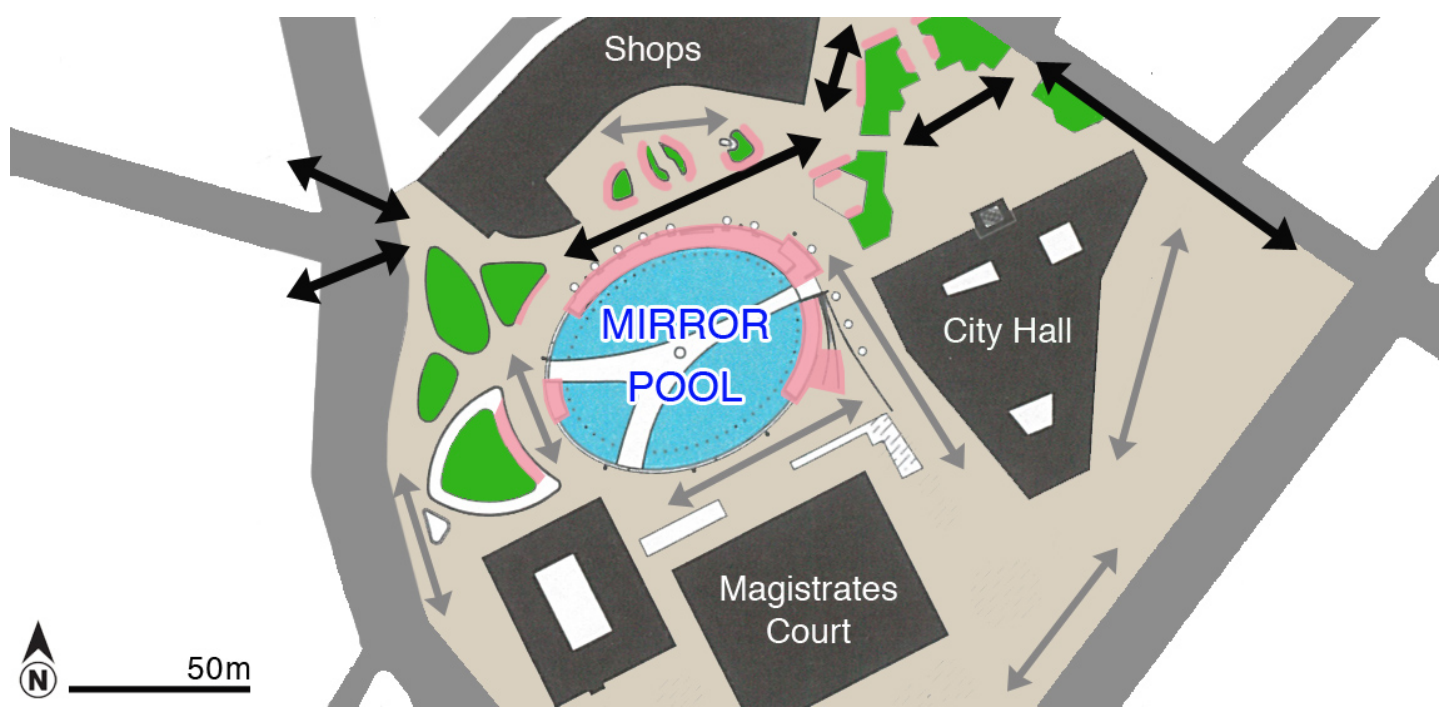

Figure 12. Pedestrian flows and main zones of stationary activities in the City Park. The arrows indicate the pedestrian flows in the area: black arrows for main flows and grey arrows for secondary flows. The pink shaded areas represent the main zones occupied by stationary activities.

We also mapped the stationary activities in the City Park's public outdoor spaces ${ }^{8}$. After observing and registering the social activities across various times, days and seasons, we identified two main zones of occupation: the first is the boardwalk of the Mirror Pool, including its internal and external borders as well as the benches. The second preferred zone is not a single, continuous area; it rather consists of several spots: the sitting surfaces located at the borders of the garden beds scattered through the City Park (Figure 12). Gardens located in close proximity to the main pedestrian flow were the most used for static activities, and the garden borders facing the inner spaces of the City Park were even more popular than those facing outwards.

With regard to the space of the Mirror Pool itself - the fountains and its surrounding boardwalk -, the case study reveals that, on an everyday basis, this area is used as a multi-functional urban space. The gradual yet constant change of the water level, in addition to the dynamic behaviour of the many fountains across the entire space, provide people with ever-changing affordances for interactions, social encounters and playful behaviours.

Overall, the most frequent setup of the Mirror Pool observed during our study was the "partial" mode, which was running in sixteen out of the 33 sessions of data collection. The common feature of the partial mode is the presence of causeways, although the size of such causeways, as well as the behaviour of the surrounding fountains, did change significantly from one session to another. This is a natural result of the dynamic character of the Mirror Pool, which is digitally set to change its water effects gradually throughout the day. Most important to our discussion, though, is the fact that even subtle changes in the setup of the water features did cause noticeable alterations in how the space was used, shared and experienced. According to our observations, one of the most dramatic features that influenced the everyday use of the Mirror Pool was the activation of the group of central water jets. During six sessions of the study, the central jets were off while the partial mode was running, meaning that the causeways offered a clear, unobstructed route to pedestrians across the Mirror Pool (Figure 13, left). With such configuration, the space of the fountain acquired an important utilitarian urban purpose: it became a thoroughfare between different areas of Central Bradford. In another six sessions, the partial mode was running while the central jets were also activated - a setup that caused a whole new approach and perception of the Mirror Pool: instead of a functional place to be traversed, the central area of the fountain was turned into a non-functional place to be contemplated, enjoyed, challenged and played with (Figure 13, right).

\footnotetext{
"By "public outdoor spaces" we mean all open spaces in the City Park, with the exception of commercial or institutional precincts that occupy the area, such as the outdoor designated space with tables for customers of the local pub and café.
} 

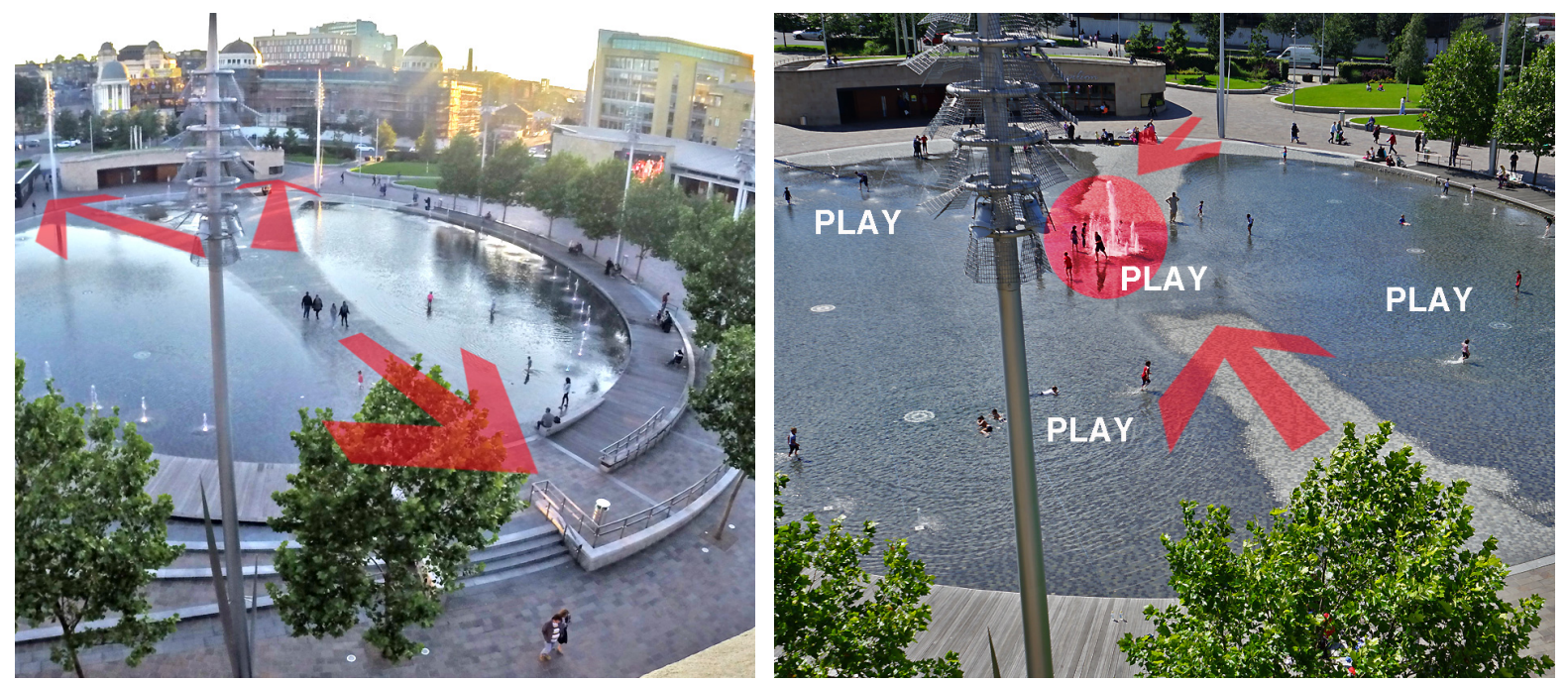

Figure 13. Two contrasting affordances of the Mirror Pool: clear and dry causeways creating alternative pedestrian routes (left); central fountains activated in the middle of the causeways, turning these utilitarian routes into spaces for play (right).

Because the central fountains occupy the area in which the causeways intercept each other, pedestrians were hardly indifferent to these fountains. From a distance people decided how to approach the space, either following their journey through the periphery of the Mirror Pool (avoiding any contact or proximity to the water), or heading towards the causeways to enjoy the scenic vistas and pleasant soundscape of the water jets, in a more playful attitude - at the risk of damping their clothes or soaking their shoes. Here the combination of lights and sounds seems to change the temporal dimension of the experienced space, triggering an extra layer of curiosity (Petrusevski and Fatah gen. Schieck 2017).

The substantial change in the way people approached the Mirror Pool - i.e., from a non-playful to a playful arena and vice-versa - was evident in the four remaining sessions of the study in which the Mirror Pool was set to the partial mode. In these sessions, we were able to observe the transition between the two contrasting situations illustrated in Figure 13. The presence of the central fountains created a target point, an area of interest that, on the one hand, attracted people to the centre of the Mirror Pool (mainly visitors in groups and children), who either stood near the water jets to observe or to photograph them, or approached even further so as to feel the water or engage through playful actions amid the jets. On the other hand, it was clear that the crossing traffic of pedestrians decreased when the central fountains were running, indicating that the playful character brought about by those fountains came at the expense of the utilitarian, non-playful use of the Mirror Pool as a thoroughfare.

The second most frequent configuration of the Mirror Pool was the "full" mode, i.e., the entire floor surface covered with water, which was observed in twelve out of the 33 sessions. In such situation, there was a slight variation in the fountains setup: the perimeter fountains ran evenly and constantly during all the twelve "full pool" sessions (as shown in Figure 10, left), while the setup of the central fountains changed from one session to another - the power of the central water jet varied from around two-metre high up to approximately fifteen-metre high, with its accompanying barrier fountains changing proportionately. However, our study reveals that, when the full mode was running, the variations in the water pressure of the central fountains did not cause important alterations in the use of the Mirror Pool. In such occasions, external factors - like the time of the day, the day of the week and the weather conditions - were much more determinant of the use and attendance levels than the behaviour displayed by the water features. With this regard, our findings confirm what is expected from open, outdoor waterbased leisure facilities: weekends tend to see a higher attendance than weekdays; afternoons are more popular than mornings and, above all that, the atmospheric conditions play a crucial role in the use of the space and the time people spend there.

The five remaining sessions of this case study took place at night, when the Mirror Pool was set to the dry mode and the laser light projections were running (Figure 10, right). An interesting situation was observed throughout these nocturnal sessions: despite the spectacular, eye-catching visual effects afforded by the animated light projections surrounded by the coloured perimeter fountains, little social activity and almost no playful behaviour were recorded on the site. In only one occasion a group of youngsters briefly played with the laser projections, while no individuals were recorded playing with the illuminated fountains whatsoever. Even though this virtual absence of players may be partially attributed to the method applied in the study (time-lapse photography with 30 seconds of interval between shootings, which means that fleeting actions performed within these intervals were not captured and therefore are not available for analysis), the in loco observations reinforce the results drawn from the series of photographs. Furthermore, the five nocturnal sessions of the study were distributed across different seasons (in March, July, August and two sessions in November), and across various days of the week, during 
which the weather conditions oscillated between clear sky with mild temperature and rainy, cold and windy nights. Thus, the general absence of players and the low levels of social encounters on the site during the night cannot be solely attributed to unfavourable external circumstances.

From the observations above, we argue that the digital technology embedded in the Mirror Pool is more effective to bring people together and to promote playful behaviours during the day. The varying layouts and multiple water effects displayed throughout the day help to create a space that is able to accommodate numerous forms of social encounters and bodily interactions, not only for children but all age groups. In this regard, the digital layer of the fountains truly supports the social life of the site and helps transform the experience of its visitors. In several sessions of the study, we observed a diverse community of users sharing the Mirror Pool and its surrounding facilities: some visitors sitting on benches, others on the boardwalk, others standing or playing; in mild afternoons or sunny weekends there were families and friends spending a long time on the place, and under much worse weather conditions we could still see children braving the cold water of the fountains, and a few adults enjoying a brief moment of playfulness on their commute (Figure 14).
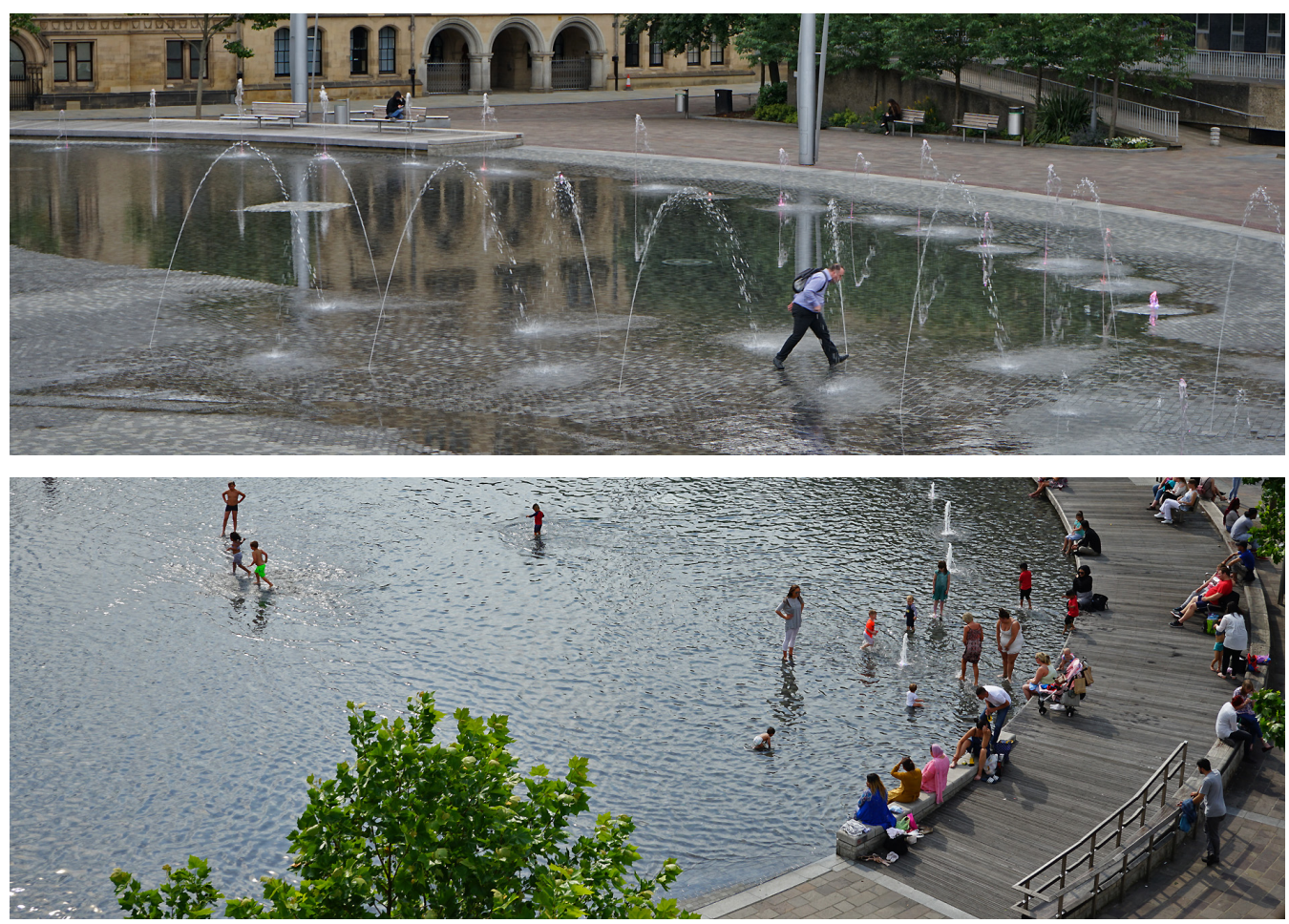

Figure 14. The playful experience of walking under the watery tunnel of the arching jets (top) and diverse types of bodily interactions and social encounters on the boardwalk and inner space of the Mirror Pool (bottom).

During the night-time, though, the digital components of the Mirror Pool - particularly the laser projections on the floor - did not animate the space as the fountains did in the daytime. In our analysis, this situation is likely due to some characteristics of the project and its urban context: firstly, the laser projections have been running every night on the site for years, which eliminates the so-called "novelty effect" (Bianchi-Bertoulze 2013) that could attract people to interact and play; secondly, the area of study is primarily frequented by residents of Bradford, who are accustomed to the visually striking features of the Mirror Pool; thirdly, part of these residents may not perceive the City Park as a safe space to stay during the night precisely because they do not usually see many people there - "people attract people" (Whyte 1980); and finally, the local weather is rarely pleasant enough to encourage people to stay around the Mirror Pool at night, even in the summer.

\section{Discussion}

In this section we discuss findings that emerged from the observation of social behaviours and embodied interactions with the Appearing Rooms and the Mirror Pool. To help inform the discussion, we will take the Granary Square fountains, in London, as a baseline for comparison.

Much can be learned through a comparative study of the same fundamental socio-spatial phenomenon - in our case, playful outdoor water features supported by digital technologies - arising from and manifested through markedly different design paradigms. In this respect, it is possible to identify a set of key differences between the two urban interfaces, and compare them with the Granary Square fountains, according to a range of design qualities, as follows: 
1. Context: while the Appearing Rooms was conceived as a piece of installation art (Bishop 2005), the Mirror Pool was built as part of an urban design regeneration project. Significant differences result from these two distinct approaches. On the one hand, the Appearing Rooms stand as an independent, self-contained artwork possessing a plug-in, add-on character (Aurigi 2017) - an installation that can be placed on virtually any physical space, provided that the basic spatial and infrastructural requirements are met, such as sufficient floor space and height, a flat horizontal surface at ground level, and the presence of power and water supplies to run the installation. On the other hand, the Mirror Pool project is essentially contextual: the whole rationale of its design derives from a larger project of urban design within which the Mirror Pool is embedded. In this case, a complex set of spatial, cultural, social, political and economic factors that are unique to the city of Bradford, and particularly to its central area, played a crucial role in the design and construction processes of the Mirror Pool.

The Granary Square fountains were, like the Mirror Pool, built as the centrepiece of a greater scheme of urban redevelopment (Ivers 2018). However, while the Mirror Pool sits in a location highly connected to pre-existent neighbourhoods and mixed functions, Granary Square's urban surroundings consist mostly of whole new districts, buildings and services, therefore subject to movement flows that are "constructed, rather than following 'natural movement' in cities" (Hillier 1996b). Moreover, Granary Square and King's Cross as a whole, despite its appearance of public space, is in fact a private property, where the presence or circulation of "different types" of people/communities may be restricted or banned. Recently, King's Cross development became one of the first property companies in Britain to acknowledge deploying facial recognition software, able to capture images of people without their consent? .

2. Temporality: the Appearing Rooms consist of a temporary installation, which has participated in several exhibitions across the world since its first appearance, in 2004. In London, the artwork has been installed every summer (from May or June until September, depending on the year) since 2007, in the same area of the Southbank Centre, as part of the Summer Festival. In contrast, both the Mirror Pool, in Bradford, and the Granary Square fountains, in London, are installed on a permanent basis, and thus possess an infrastructural character - even though the Mirror Pool's controlling software is programmed to switch off the water and light effects of the facility daily from midnight to 7.00am for maintenance, security and energy saving reasons.

3. Scale: the two splash facilities of our case studies differ greatly in terms of their physical dimensions: while the water jets of the Appearing Rooms are installed on a square platform measuring approximately 7 X 7 metres (hence totalling around 50 square metres), the wet surface of the Mirror Pool covers an extensive oval area (maximum dimensions of 75 metres long and 58 metres across), totalling approximately 3,600 square metres - which makes the Mirror Pool the largest urban water feature in the UK (City Park 2019; Landezine 2014). Since we believe that the physical and spatial properties of playful urban interfaces perform a crucial role in shaping the lived experiences around them, further insights may potentially be gained by analysing two projects with such a dramatic difference in scale.

4. Technological mediation and access: as situated media, the case studies also differ in the way they employ digital technologies to mediate the players' experiences. The computer that controls the Appearing Rooms remains in the "backstage" of the playful arena, hidden inside a metallic shed near the installation, its sole function being controlling the water jets choreography. This characterizes a back end technological approach to the mediation of the interactions. In contrast, the digital components employed in the Mirror Pool - such as motion sensors, laser projections and especially the site-specific media artwork Another Life - tend to take centre stage and drive the urban experience, characterizing an urban situation where the situated technology is both back end and front end. For the sake of illustration and comparison, the Snake game at the Granary Square fountains points to yet another model of mediated experience: in this case, the digital interactive technology is not directly accessible, as people need (a) an internet-enabled mobile device; (b) a pre-installed mobile app (the Granary Squirt); and (c) access to the local Wi-Fi network.

\section{Urban fountains in the digital turn: from contemplative to playful interfaces}

From a bodily and sensory standpoint (considering, of course, favourable weather conditions), traditional, contemplative water fountains tend to subtly induce people to find a comfortable place nearby - ideally a place to sit - and, once settled in that place with their bodies relaxed, people can spend time chatting with others or enjoying the moment on their own, while observing the flow of water in the fountain and the flow of other people around it. Depending on the urban context and the design of the fountain itself, listening to the water jets can become a significant part of the experience. Going even further into the sensory realm, certain circumstances, like people's position around the fountain and the local atmospheric conditions, may render the encounter an also tactile and olfactory experience; for example, the wind can carry droplets of water towards people nearby, or may equally disperse intangible elements of the fountain across the environment, such as the odour of the chemicals used to treat the water. At any rate, such traditional typology of urban fountains usually does not encourage an active, physical and playful encounter between people and the water features. In fact, many mechanisms have been

' https://www.theguardian.com/uk-news/2019/aug/12/regulator-looking-at-use-of-facial-recognition-at-kings-cross-site 
developed to keep people away from the water, ranging from design decisions (built structures that hinder direct access to the fountain) up to more or less explicit forms of law enforcement, such as warning signs, security guards and surveillance cameras.

The design of the emergent generation of playful, interactive urban water features, such as the Appearing Rooms, the Mirror Pool and the Granary Square fountains, increasingly relies on digital technologies to disrupt or augment the ways people use their own bodies to approach and engage with the water and with other people in outdoor urban spaces. Instead of the bodily-detached onlookers found around conventional fountains, this new generation of playful, technologically enhanced fountains encourages individuals to assume a "physically" active and participatory role. The sense of presence is reinforced and acquires a new meaning through a complex web of material, bodily-kinaesthetic and social encounters that unfold on and around the fountain over time. We may characterise this emergent typology of interactive water features as platforms for multi-layered bodily, spatial and social encounters, since the fountain defines an interaction space (Fischer and Hornecker 2012) that potentially enables a multitude of shared encounters and spatial negotiations - not only between players acquainted with each other but, most interestingly, encounters between people who happen to meet for the first time during the very act of play.

Playing with an interactive fountain is hardly a solely individual experience: as urban facilities located in shared, open spaces of the city, the fountains create an opportunity for citizens to engage in a variety of activities, ranging from explicit playful behaviours, with a sheer performative character (Reeves 2011; Rico and Brewster 2010) for example moving in and out of the spaces defined by the water jets - up to more implicit forms of play, such as observing or photographing from a distance the players amid the water features. Importantly, these bodily and playful interactions with the fountain may also stimulate other forms of social interaction among nearby people who are not physically engaged with the water features, for example through the so-called "triangulation" (Whyte 1980), in which an interface (in this case, the fountains) prompts strangers to talk to each other, or through "shared encounters", where a sense of performative co-presence arises from the "mutual recognition of spatial or social proximity" (Willis et al. 2010). In the selected studies we found that, when visiting the Appearing Rooms or the Mirror Pool in pairs or groups, at least one person of the party often stayed outside, at the close vicinities of the fountain, while other members of the group engaged with the water features. In such situations, the person(s) who remained outside the fountain usually took up impromptu social roles, such as photographing or filming the players, looking after their personal belongings or engaging in a conversation with someone else - not rarely a member of another social group. At times of high attendance, the opportunities of social encounters and informal contacts between strangers around interactive fountains are naturally multiplied.

From a socio-spatial perspective, interactive fountains may be contrasted with their non-interactive counterparts by applying the analogy of centripetal and centrifugal forces. Accessible urban fountains designed to encourage playful behaviours - as those investigated in this article - usually possess what we call a centripetal socio-spatial character: these fountains tend to draw people towards their inner interaction space (Fischer and Hornecker 2012), offering players the possibility to engage through whole-body interactions with the materiality of both the water and the built environment (Figure 15, left). Contemplative, non-interactive fountains, on the contrary, tend to possess what we call a centrifugal socio-spatial character: they encourage people to assume the role of spectators by keeping some distance from the water (Figure 15, right). Centrifugal fountains function as pure landscaping elements, whose scenic or topological qualities tend to overshadow any sense of bodily-kinaesthetic experience or playful interactions. Importantly, both centripetal and centrifugal fountains have the potential to trigger a web of social encounters, for both typologies define a place where a sense of co-presence is experienced. Though, while centripetal fountains stand as porous, accessible urban interfaces in which players are protagonists and playing is always a possibility for those in the spatial surroundings, in the case of centrifugal fountains spectators dominate the scene, and accessing or playing with the fountain itself is not possible and/or not allowed. Since contemplative fountains are not supposed to be physically accessed or played with (see, for example, Trafalgar Square in Figure 1), the spatial quality of its urban surroundings - expressed in amenities such as seating spaces, green and shaded areas, and protection from the weather - becomes an ever more important factor for a number of reasons: bringing people together, making them stay longer in the area, fostering casual encounters and person-to-person interactions. 

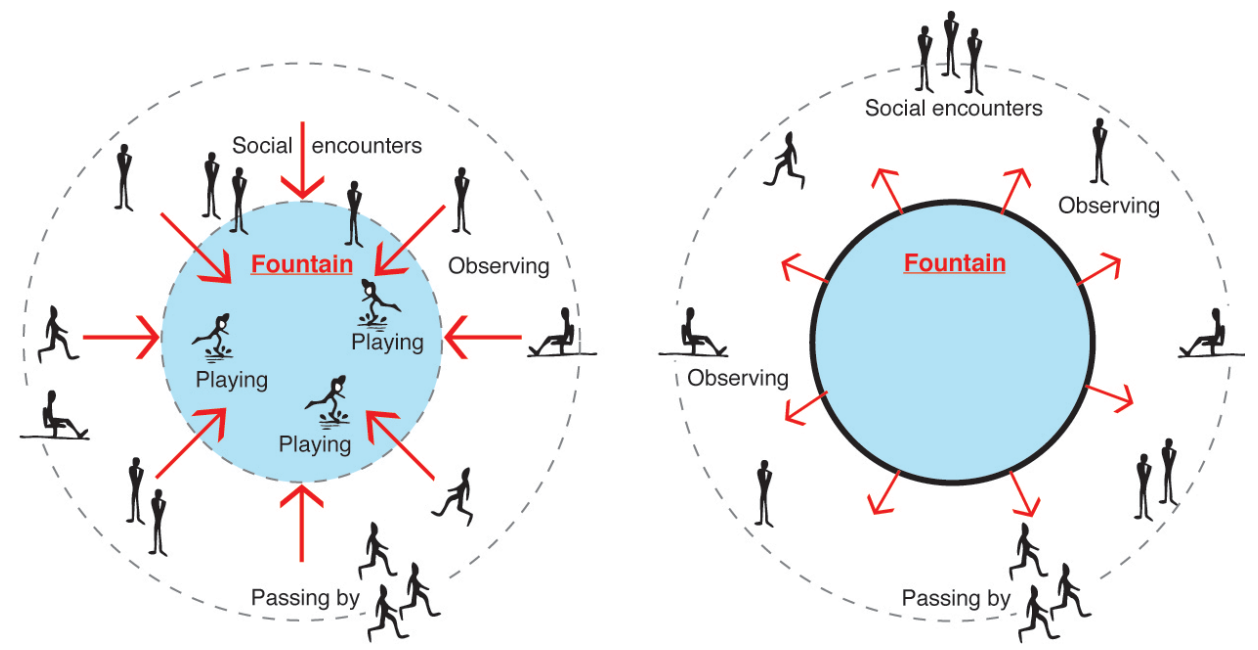

Figure 15. Diagrams of two contrasting design affordances: a playful fountain with a centripetal socio-spatial character (left) and a contemplative fountain with a centrifugal character (right). The red arrows represent, in each case, the typical socio-spatial and bodily forces at play that either draw people to the space of the fountain, on a convergent fashion (left) or keep people away from the fountain, on a divergent fashion (right). Whereas the centripetal model (left) features porous socio-spatial boundaries (represented by the dashed inner circle), in the centrifugal model (right) these boundaries are clearly demarcated and define a secluded space.

\section{Broadening the scope: living and playing in the "smart city" - Concluding remarks}

In this paper, we have argued for rethinking the notion of "smart cities" as playable cities. We presented two case studies of playful urban media installations that enable "unplanned" encounters in the city: the Appearing Rooms and the Mirror Pool. These installations share some important characteristics:

1. They are situated and fixed interactive interfaces, therefore embedded in the urban fabric;

2. They are water-based installations;

3. They encourage playful and whole-body interactions.

We analysed emergent playful interactions at different levels and scales: from the micro scale of the bodily engagement to the macro scale of the spatial and social configurations. The Appearing Rooms and the Mirror Pool were then contrasted with a third example of water-based interface (the Granary Square fountains) that shares similarities but also essential differences. These three cases illustrate an emergent use of situated technologies coupling urban design, computing resources, hydraulic engineering and interaction design to create conditions for playful experiences in urban outdoor settings. As such, these interfaces redefine the very notions of "urban play" and "urban fountains" regarded as infrastructure: what they mean and how we should approach, share and experience them. More than simply interactive water features or splash facilities, urban structures like the Appearing Rooms and the Mirror Pool - and unlike the Granary Square fountains - are more faithfully characterised as situated urban media interfaces, able to cater to a wide range of bodily and playful interactions, often combined with equally diverse forms of social encounters and spatial negotiations. Our case studies suggest that the digital should be coupled with a careful consideration of the spatial, physical, material and bodily aspects of interactions, which are fundamental to our lived experience of the city.

Addressing the lived experience entails a due consideration of the spatial, material and bodily dimensions that ultimately define how we interact with the world. By exploiting the sheer materiality of water, the Appearing Rooms and the Mirror Pool succeed in heightening such sense of lived experience. Both interfaces subtly invite urban inhabitants to (re)discover their own spaces through a palpable, corporeal, dynamic encounter with the water - an element whose sensory richness and playful possibilities can be experienced in many forms. At the same time, and particularly important in the context of smart cities, is the fact that the Appearing Rooms and the Mirror Pool make use of computing technologies to encourage a wide range of potential experiences and encounters in public outdoor settings. Building on the concept of "smart spaces" set out in the Introduction, we argue that situated urban media interfaces like the Appearing Rooms and the Mirror Pool are potential enablers of real smart spaces: by transcending the conventional, data-driven notion of "smart cities" and incorporating the idea of play through bodily interactions and social encounters, these interfaces help create the conditions for meaningful urban experiences to emerge.

We have argued, in the Background section, that urban interactive installations - including those enhanced by media technologies - are far from being an automatic or ultimate solution for the activation or "creation" of lively and socially thriving places. On a broader historical perspective, urban spaces are resilient settings: over time, they 
stage new forms of social encounters while accommodating new types of conflicts and negotiations. These processes tend to reflect and respond to manifold contextual aspects, including trends, fads and fashions brought about by emerging technologies. Naturally, any spatial element (for example, a media installation encouraging playful interactions) that prevails over the others is not necessarily the most suitable alternative for a socially diverse and rich urban setting. However, our case studies suggest that permanent, site-specific installations, like Bradford's Mirror Pool, which are planned and designed as part of a broader urban design scheme (i.e. taking into account the manifold factors that are unique to their urban settings), have better chances to become embedded elements of their environment, bringing the social and civic benefits associated with lively places. Playful interactions become, in this context, a rich and multi-layered design paradigm. Play turns itself into the trigger for people's deeper involvement with their surroundings, considered both from the corporeal, social and spatial perspectives. On the contrary, plug-in, self-contained installations, like the Appearing Rooms, despite their potential to enable smart spaces, risk not being able to sustain social life after the "novelty effect" has passed.

Coupling the conceived space with the lived space, or more specifically a playful interface with interactions and play, is hardly an automatic or clear-cut process. This seems even more evident in the case of situated media technologies, as illustrated by the game in Granary Square. Continuing efforts and investments must be made in planning, commissioning, curating, advertising and managing urban media initiatives, particularly those installed on a permanent or long-term basis. A good example is the large urban screen installed at Federation Square, Melbourne, which is considered a successful application of urban media: this success is partly due to an active public programme of local activities and events devised to encourage social diversity and participation on the site (Papastergiadis et al. 2013). Likewise, some British towns have adopted a more playful approach to the use of urban screens (O’Hara et al. 2008).

With the rise of 'smart cities' phenomena, and as the scope of urban interaction design and research changes to respond to the city scale and context, we believe that city managers and practitioners involved in design decisions of urban spaces need to explore an additional level of knowledge that relates to the material, temporal and embodied aspects of interactions, in addition to the other important aspects that have informed their decisions so far - for example the social, spatial, political, cultural and economic dimensions of urban spaces.

Building on our case studies and discussions on urban play in the context of smart cities, we also believe that reimagining and reinforcing the notion of play in cities, through digital or non-digital interfaces (such as the Appearing Rooms and the Mirror Pool), can offer a community-oriented and place-based approach to smart cities. In this regard, our exploratory research offers material that can help inform design decisions for smart cities by a range of stakeholders, including city managers, urban designers, architects, artists and interaction designers.

\section{References}

Ackermann, J. et al. 2016. Introductions: PLAYIN' THE CITY: Artistic and Scientific Approaches to Playful Urban Arts. Navigationen: Playin' the city, Jg. 16.

Afonso, A. et al. 2019. Flowing Bodies: Exploring the Micro and Macro Scales of Bodily Interactions with Urban Media Installations. Proceedings of the Designing Interactive Systems Conference (DIS '19), San Diego, CA, USA.

Argent St. George. 2001. Principles for a human city. A document prepared by Argent St George, the selected developer for King's Cross Central, and the landowners, London and Continental Railways and Exel. $3^{\text {rd }}$ Edition, July 2001. Available at:

https://www.kingscross.co.uk/media/Principles_for_a_Human_City.pdf (accessed 24.09.2019)

Aurigi, A. 2017. Space is not a platform - foregrounding place in smart urban design. In: Zammit A; Kenna, T. (Eds.). Enhancing Places Through Technologies: Proceedings from the ICiTy conference, Valletta, Malta - 1819 April, 2016, p. 7-18.

Barker, A. et al. 2014. The Great Meeting Place: A Study of Bradford's City Park. Report. University of Bradford.

Behrens, M. et al. 2013. Exploring the Effect of Spatial Layout on Mediated Urban Interactions. In PerDis 2013. ACM.

Behrens, M. et al. 2015. Designing Media Architectural Interfaces for Interactions in Urban Spaces. In: Foth, M. et al. (Eds.). Citizen's Right to the Digital City. Springer Science+Business Media Singapore 2015.

Benford, S.; Giannachi, G. 2011. Performing Mixed Reality. The MIT Press. 
Bianchi-Berthouze, N. 2013. Understanding the Role of Body Movement in Player Engagement. HumanComputer Interaction, 2013, Volume 28, pp. 40-75.

Bishop, C. 2005. Installation art: a critical history. London: Tate.

Borden, I. 1996. Strangely familiar: narratives of architecture in the city. London: Routledge.

Borden, I. 2001. Another pavement, another beach: skateboarding and the performative critique of architecture. In I. Borden et al (Eds.), The unknown city: contesting architecture and social space: a Strangely Familiar project. Cambridge, Mass.; London: MIT Press.

Borden, I. 2014. The role of risk in urban design. In Carmona, M. (Ed.). Explorations in Urban Design: An Urban Design Research Primer. London: Routledge.

Borden, I. 2019. Skateboarding and the city: a complete history. Bloomsbury.

Caldwell, G. A.; Foth, M. 2014. DIY media architecture: open and participatory approaches to community engagement. In Proceedings of the 2nd Media Architecture Biennale Conference: World Cities (MAB '14) (pp. 1-10). New York, NY, USA: ACM.

Caillois, R. 2001. Man, play, and games. Urbana: University of Illinois Press.

Carvalho, L. 2015. Smart Cities from scratch? A socio-technical perspective. Cambridge Journal of Regions, Economy and Society, Volume 8, Issue 1, March 2015, pages 43-60. Available at: https://doi.org/10.1093/cjres/rsu010 (accessed 02.08.2019).

Catapult Future Cities. 2017. Smart City Strategies. A Global Review. Available at: https://futurecities.catapult.org.uk/wp-content/uploads/2017/11/GRSCS-Final-Report.pdf (accessed 30.07.2019)

City Park. 2019. City Park Mirror Pool. Available at: http://www.cityparkbradford.com/mirror-pool/ (accessed 11.02.2019).

de Lange, M.; de Waal, M. (Eds.). 2019. The Hackable City: Digital Media and Collaborative City-Making in the Network Society. Springer.

de Waal, M. 2014. The City as Interface: How New Media Are Changing the City. Rotterdam: Nai010.

Digital Water Pavilion. 2008. Carlorattiassocciati. Available at:

https://carloratti.com/project/digital-water-pavilion/ (accessed 15.03.2019)

Dubberly, H. et al. 2009. What is interaction? Are there different types?, Interactions, 16(1), pp. 69-75.

Fatah gen Schieck, A. et al. 2008. The Urban Screen as a socialising platform: exploring the role of place within the urban space. In F. Eckardt, J. Geelhaar, L. Colini, K. S. Willis, K. Chorianopoulos, R. Hennig (Eds.). MEDIACITY. Situations, Practices and Encounters (pp. 285-307). Frank \& Timme GmbH.

Fischer, P. T.; Hornecker, E. 2012. Urban HCI: spatial aspects in the design of shared encounters for media facades. In CHI 2012.

Fritsch, J.; Brynskov, M. 2011. Between experience, affect, and information: Experimental urban interfaces in the climate change debate. In M. Foth, L. Forlano, C. Satchell, \& M. Gibbs (Eds.). From social butterfly to engaged citizen (pp. 115-134). Cambridge, MA: MITP.

Gillespies. 2019. Bradford City Park. Available at:

https://www.gillespies.co.uk/projects/bradford-city-park (accessed 01.02.2019).

Haque Design + Research. 2012. Another Life. Available at:

http://www.haque.co.uk/anotherlife.php (accessed 12.02.2019).

Hein, J. 2019. Appearing Rooms. Available at:

http://www.jeppehein.net/pages/project_id.php?path=works\&id=127 (accessed 11.02.2019).

Hillier, B., and Hanson, J. 1984. The social logic of space. Cambridge University Press, Cambridge. 
Hillier, B. 1996a. Space is the machine: a configurational theory of architecture. Cambridge University Press, Cambridge.

Hillier, B. 1996b. Cities as movement economies. Urban Design International, 1 (1), p. 41-60.

Huizinga, J. 1955. Homo ludens: a study of the play-element in culture. Boston: Beacon Press.

Innocent, T. 2016. Play and placemaking in urban art environments. In: Proceedings of the 3rd Conference on Media Architecture Biennale. MAB16. Sydney, ACM.

Innocent, T. 2020. Citizens of Play: Revisiting the Relationship Between Playable and Smart Cities. In: Nijholt, A. (Ed.). Making Smart Cities More Playable: Exploring Playable Cities. Springer, p. 25-49.

Ivers, C. 2018. Staging Urban Landscapes: The Activation and Curation of Flexible Public Spaces. Birkhauser.

Kitchin, R. 2014. The Real-Time City? Big Data and Smart Urbanism. GeoJournal. Springer Verlag.

Kitchin, R. 2015. The Promise and Perils of Smart Cities. Computers \& Law 26(2).

Kress, G., and Cowan, K. 2017. From making meaning to meaning-making with writing: Reflecting on fouryear-olds at play. In: Østergren-Olsen, D., and Friis Larsen, K. (Eds.). Literacy and Learning in Primary School. Copenhagen: Dafolo.

Kwastek, K. 2013. Aesthetics of interaction in digital art. MIT Press.

Landezine. 2014. Bradford's City Park. Available at:

http://www.landezine.com/index.php/2014/08/bradfords-city-park-by-gillespies/ (accessed 11.02.2019).

Larssen, A. T. et al. 2007. Experiential Bodily Knowing as a Design (Sens)-ability in Interaction Design. In: Proceedings of the 3rd European Conference on Design and Semantics of Form and Movement (DeSForM '07).

Lefebvre, H. 1991. The production of space. Blackwell, Oxford.

Lennard, S. H. C.; Lennard, H. L. 1984. Public life in urban places: social and architectural characteristics conducive to public life in European cities. Southampton, N.Y.: Gondolier Press.

Levisohn, A.; Schiphorst, T. 2011. Embodied engagement: Supporting movement awareness in ubiquitous computing systems, Ubiquit. Learn. Int. J., 3(4), pp. 97-112.

Müller, J. et al. 2010. Requirements and design space for interactive public displays. In Proceedings of the International Conference on Multimedia (pp.1285-1294).

Niederland, W. G. 1989. River Symbolism, Part I. In: Stein, Howard F. and Niederland, William G. (Eds.). Maps from the Mind: Readings in Psychogeography. University of Oklahoma Press.

Nijholt, A. 2017. Towards Playful and Playable Cities. In: Nijholt, A. (Ed.). Playable Cities: The City as a Digital Playground. Springer, p. 1-20.

Nijholt, A. 2020. Making Smart Cities More Playable. Exploring Playable Cities. Springer.

O'Hara, K. et al. 2008. Understanding collective play in an urban screen game. In Proceedings of CSCW 08, San Diego, CA, USA.

Papastergiadis, N. et al. 2013. Mega Screens for Mega Cities. Theory, Culture \& Society, 30(7/8), p. 325-341.

Pérez de Arce, R. 2018. City of play: an architectural and urban history of recreation and leisure. London: Bloomsbury.

Petrusevski, I.; Fatah gen. Schieck, A. 2017. Enhancing interaction within urban settings using light and sound stimuli. In Yamu, C; Poplin, A.; Devish, O.; de Roo, G. (Eds.). The Virtual and the Real in Planning and Urban Design Perspectives, Practices and Applications. Routledge, p. 252-266.

Playable City. 2019. Available at: 
https://www.playablecity.com (accessed 01.08.2019).

Pop, S. et al. 2016. What urban media art can do: why when where \& how. Avedition.

Preece, J. et al. 2002. Interaction Design: Beyond Human-Computer Interaction. John Wiley \& Sons.

Reeves, S. 2011. Designing interfaces in public settings: Understanding the role of the spectator in HumanComputer Interaction. Springer.

Rico, J.; Brewster, S. Usable Gestures for Mobile Interfaces: Evaluating Social Acceptability. In CHI 2010.

Sicart, M. 2016. Play and the City. In Introductions: PLAYIN' THE CITY: Artistic and Scientific Approaches to Playful Urban Arts. Navigationen: Playin' the city, Jg. 16.

Stevens, Q. 2007. The ludic city: exploring the potential of public spaces. London: Routledge.

Tekin, B. ;Reeves, S. 2017. Ways of Spectating: Unravelling Spectator Participation in Kinect Play. In CHI 2017 ACM.

The Fountain Workshop. 2019. Bradford City Park. Available at:

https://www.fountains.co.uk/project/bradford-mirror-pool (accessed 01.02.2019).

The Guardian. 2019. Pink seesaws reach across the divide at US-Mexico border. Available at: https://www.theguardian.com/us-news/2019/jul/30/pink-seesaws-reach-across-divide-us-mexico-border (accessed 01.08.2019).

Urbanowicz, K.; Lucyna, N. 2012. Media architecture - participation through the senses. In Proceedings of the Media Architecture Biennale (MAB '12).

van Vleet, M.; Feeney, B. C. 2015. Play behavior and playfulness in adulthood. Social and Personality Psychology Compass, Vol. 9, 11, p. 630-643.

Verhoeff, N. 2015. Mobile media architecture: Between infrastructure, interface, and intervention. Observatorio $\left(O B S^{*}\right)$, Vol. 9, p. 71-84.

Whyte, W. 1980. The social life of small urban spaces. Conservation Foundation.

Willis, K. S. et al. 2010. Shared encounters. Springer.

Zielinska-Dabkowska, K. 2019. Urban lighting masterplan: origins, definitions, methodologies and collaborations. In Davoudian, A. (Ed.). Urban Lighting for People: Evidence-Based Lighting Design for the Built Environment. RIBA Publishing. 